\title{
STATIC BEHAVIOR OF AXIALLY COMPRESSED CIRCULAR CONCRETE FILLED CFRP-STEEL TUBULAR (C-CF-CFRP-ST) COLUMNS WITH MODERATE SLENDERNESS RATIO
}

\author{
Q.L. Wang ${ }^{1, *}$, S.E. Qu ${ }^{2}$, Y.B. Shao ${ }^{3}$ and L.M. Feng ${ }^{4}$ \\ ${ }^{1}$ Professor, School of Civil Engineering, Shenyang Jianzhu University, Shenyang, P. R. China \\ ${ }^{2}$ Graduate Student, School of Civil Engineering, Shenyang Jianzhu University, Shenyang, P. R. China \\ ${ }^{3}$ Professor, School of Mechatronic Engineering, Southwest Petroleum University, Chengdu, P. R. China \\ ${ }^{4}$ Graduate Student, School of Civil Engineering, Shenyang Jianzhu University, Shenyang, P. R. China \\ *(Corresponding author: E-mail: ceqlwang@sjzu.edu.cn)
}

Received: 19 January 2015; Revised: 7 October 2015; Accepted: 5 January 2016

\begin{abstract}
Thirty-two specimens are experimentally tested in this paper to study the static performance of axially compressed circular concrete filled CFRP-steel tubular (C-CF-CFRP-ST) columns. The tested results indicate that, for columns with relative small slenderness ratio, failure is dominated by the strength loss of the materials. However, for columns with relative large slenderness ratio, failure is controlled by instability. The load versus deflection curves at the mid-height of the composite column can be divided into three stages, i.e., elastic, elasto-plastic and softening stage. Analyses of the tested results show that distribution of longitudinal strains in the steel tube over depth on the cross-section is approximately linear, and the steel tube and its outer CFRP material can cooperate both longitudinally and transversely. The longitudinal strain and the transverse strain at a point have opposite signs, and the steel tube under longitudinal tension has no transverse confinement effect on its concrete. The Deformed modes of the columns, the axial load verses deflection curves at the mid-height, the axial load verses axial shortening curves and the stresses in the steel tube are simulated by using finite element method. The calculated results agree well with the experimental results to prove the accuracy of the finite element model. Stresses in the concrete, the steel tube and the CFRPs are analyzed by using finite element method. The numerical results show that the interaction force between the steel tube and the concrete decreases gradually from compressive region to tensile region. The adhesive strength between the concrete and the steel tube has little effect on the critical buckling load and on the elastic stiffness of the columns. Equation for calculating the critical buckling load of the composite columns is presented, and the estimated results agree well with the experimental results.
\end{abstract}

Keywords: Circular CFRP-steel tube, In-filled concrete, Axially compressed columns with moderate slenderness ratio, Static performance, Critical buckling load

DOI:10.18057/IJASC.2016.12.3.4

\section{INTRODUCTION}

Fiber Reinforced Plastic (FRP) has been used in many engineering structures due to its advantages of high strength/weight ratio, good corrosion resistance, ease of installation, more and more cheaper cost and so on, in which Concrete Filled FRP Tubular (CF-FRP-T) structure or FRP strengthened concrete structure is a typical example. There are many research reports on CF-FRP-T (Wang and Restrepo [1]; Fam and Rizkalla [2]; Teng et al. [3]; Karabinis et al. [4]; Rousakis et al. [5]; Yu. et al. [6]; Yu. et al. [7]; Jiang and Wu [8]). CF-FRP-T structures have better corrosion resistance. However, the failure mode of CF-FRP-T structures has brittle characteristics in most cases, and the load carrying capacity in the transverse direction for this structure is weak.

As one typical style of the steel-concrete composite structures, Concrete Filled Steel Tubular (CFST) structures are widely used in civil engineering, and they show good constructional efficiency. The research work in this field has been studied systematically in the literature. Besides the systematic investigations on the static and the hysteretic behavior of the components and the connections (Han [9]; Han et al. [10]; Han et al. [11]; Han et al. [12]; Han and Li [13]), fire resistance (Han [14]), torsion performance (Han et al. [15]) and local compression (Han et al. [16]) 
of this structure are also reported. Comparing with the CF-FRP-T, CFST has higher shearing load carrying capacity. However, the outer surface corrosion of the steel tube cannot be ignored when CFST is used in a corrosive environment, and some corresponding research studies in this field have been reported in recent years (Han et al. [17]; Han et al. [18]).

In many engineering fields, the FRP-metal composite tanks or tubes have been used widely, such as gas tank used in motor vehicle (as shown in Figure 1, where GFRP refers to Glass Fiber Reinforced Plastic) and pipeline system for transporting high pressure gas or liquid used in municipal engineering or chemical engineering. Sometimes, petroleum pipeline system after corrosion is also reinforced with CFRP (Carbon Fiber Reinforced Plastic), which can save much cost compared to the measure of replacing the corroded tube with a new one. CFRP-metal tube can also be used in civil engineering, for example, by infilling concrete into CFRP-steel composite tube (Che et al. [19]), or by using CFRP to strengthen damaged CFST (Tao et al. [20]). Both of the above methods can form the so-called Concrete Filled CFRP-Steel Tubular (CF-CFRP-ST) structures. CF-CFRP-ST structures have the advantages of both the CFST and the CF-FRP-T structures, and the CF-CFRP-ST structures can also avoid the respective deficiency of the CFST and the CF-FRP-T structures to some degree. Recent study shows that CF-CFRP-ST has satisfactory fire endurance time when adequate fire resistant measures have been taken (Tao et al [21]).

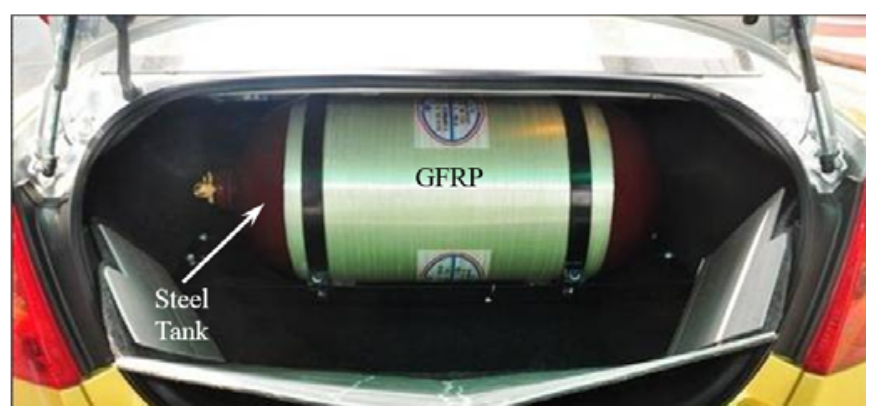

Figure 1. Gas Tank Used in Motor Vehicle

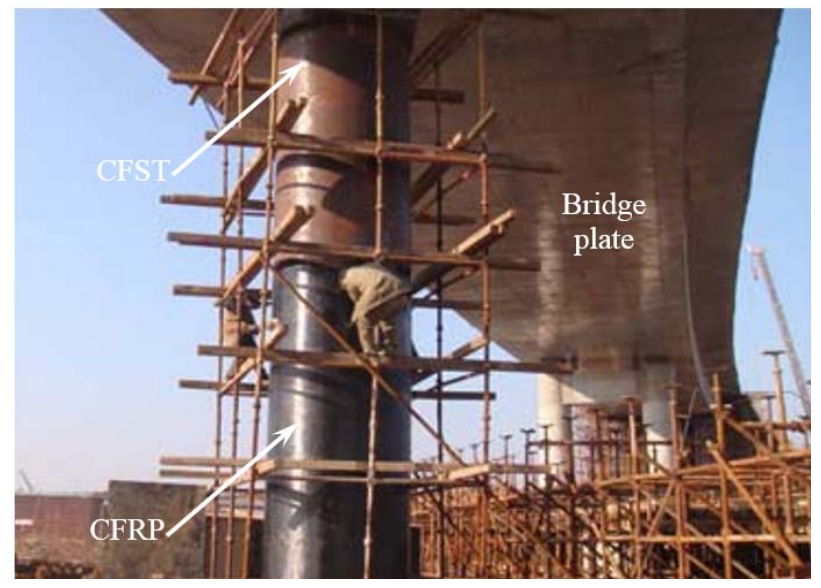

Figure 2. An Engineering Practice of C-CF-CFRP-ST Columns Used in Nanjing City, Jiangsu Province, P. R. China

There are many research studies about CF-CFRP-ST structures in the literature, and these studies mostly focus on Circular CF-CFRP-ST (C-CF-CFRP-ST) stub columns (Xiao et al. [22]; Choi and Xiao [23]; Park et al. [24]; Hu et al. [25]; Li et al. [26]; Teng et al. [27]), C-CF-CFRP-ST flexural members (Wang and Shao [28]), Square CF-CFRP-ST (S-CF-CFRP-ST) stub columns (Tao et al 
[29]; Park et al. [30]; Sundarraja and Ganesh [31]; Sundarraja and Ganesh [32]; Sundarraja and Ganesh [33]; Wang and Shao [34]) and S-CF-CFRP-ST flexural members (Sundarraja and Ganesh [35]; Wang et al. [36]). More applications in practical engineering are columns with large slenderness ratio (as shown in Figure 2) although corresponding research is quite scarce. For axially compressed stub columns (slenderness ratio $\lambda \leq 3$ ), compressive buckling does not occur in general, and its load carrying capacity is determined by the material properties and the combination effect, while for axially compressed columns with moderate slenderness ratio, i. e., $\lambda>3$, its critical buckling load is generally determined by stability, which is necessary to be studied specially.

To understand the static performance of the axially compressed C-CF-CFRP-ST columns with moderate slenderness ratio, 32 composite specimens with both transverse CFRP and longitudinal CFRP are tested and the details are introduced in this paper. Axial load $(N)$ versus deflection at the mid-height $\left(u_{\mathrm{m}}\right)$ curves, cooperation between the steel tube and the CFRP and plane section assumption of the composite specimens are analyzed. Furthermore, the finite element software ABAQUS is used to simulate the deformed modes and the $N-u_{\mathrm{m}}$ curves of the composite columns. The distributions of the stress and the strain, the effects of adhesive strength between the steel tube and the concrete, and the interaction force $(p)$ between the concrete and the steel tube are also analyzed. Finally, the equation for calculating the critical buckling load of the axially compressed $\mathrm{C}-\mathrm{CF}-\mathrm{CFRP}-\mathrm{ST}$ columns with moderate slenderness ratio is given.

\section{EXPERIMENTAL PROGRAM}

\subsection{General}

In overall, tests on 32 axially compressed C-CF-CFRP-ST columns are conducted, and the basic parameters considered for these specimens include $\lambda$ and strengthening factor of the longitudinal CFRP $(\eta)$ (Wang and Shao [28]), respectively, where

$$
\begin{aligned}
& \lambda=4 L / D_{\mathrm{s}} \\
& \eta=A_{\mathrm{cfl}} f_{\mathrm{cfl}} /\left(A_{\mathrm{s}} f_{\mathrm{y}}\right) \\
& f_{\mathrm{cfl}}=E_{\mathrm{cf}} \varepsilon_{\mathrm{cflr}}=2300 \mathrm{MPa}
\end{aligned}
$$

where $L$ is the length of the column; $D_{\mathrm{s}}$ is the outer diameter of the steel tube. $A_{\text {cfl }}$ and $f_{\text {cfl }}$ are the cross-sectional area and the ultimate tensile strength of the longitudinal CFRP, respectively. $A_{\mathrm{s}}$ and $f_{\mathrm{y}}$ are the cross-sectional area and the yield strength of the steel tube, respectively. $E_{\mathrm{cf}}$ and $\varepsilon_{\text {cflr }}$ are the elasticity modulus of CFRP and the rupture strain of the longitudinal CFRP, respectively. In this study, $\varepsilon_{\text {cflr }}=10000 \mu \varepsilon$, and the determination of $\varepsilon_{\text {cflr }}$ can be referred to the corresponding reference (Wang and Shao [28]).

The specimens' details are provided in Table 1. In the nomenclature of the specimens as listed in Table 1, CC means Circular Column. Letters A, B, C, D, E, F, G and H denote the different lengths of the columns: $400 \mathrm{~mm}, 530 \mathrm{~mm}, 600 \mathrm{~mm}, 800 \mathrm{~mm}, 1200 \mathrm{~mm}, 1800 \mathrm{~mm}, 2400 \mathrm{~mm}$ and $3000 \mathrm{~mm}$, respectively. Number $0,1,2$ or 3 refers to the number of the longitudinal CFRP layer(s) $\left(m^{\prime}\right) . m$ is 
number of the transverse CFRP layer. $t_{\mathrm{s}}$ is the wall thickness of the steel tube, and $N_{\mathrm{u}, \mathrm{cr}}^{\mathrm{t}}$ is the tested value of the critical buckling load of the C-CF-CFRP-ST columns. $\xi_{\mathrm{s}}$ is the confinement factor of the steel tube (Han [9]). $\xi_{\text {cf }}$ is the confinement factor of the transverse CFRP tube (Che et al. [19]), where

$$
\begin{aligned}
& \xi_{\mathrm{s}}=A_{\mathrm{s}} f_{\mathrm{y}} /\left(A_{\mathrm{c}} f_{\mathrm{ck}}\right) \\
& \xi_{\mathrm{cf}}=A_{\mathrm{cft}} f_{\mathrm{cft}} /\left(A_{\mathrm{c}} f_{\mathrm{ck}}\right) \\
& f_{\mathrm{ck}}=0.67 f_{\mathrm{cu}} \\
& f_{\mathrm{cft}}=E_{\mathrm{cf}} \varepsilon_{\mathrm{cftr}}=1265 \mathrm{MPa}
\end{aligned}
$$

where $A_{\mathrm{c}}$ and $f_{\mathrm{ck}}$ are the cross-sectional area and the characteristic axial compressive strength of the concrete, respectively. $A_{\text {cft }}$ and $f_{\text {cft }}$ are the cross-sectional area and the ultimate tensile strength of the transverse CFRP, respectively. $f_{\mathrm{cu}}$ is the cubic strength of the concrete specimen. $\varepsilon_{\text {cftr }}$ is the rupture strain of the transverse CFRP ( $\left.\varepsilon_{\text {cftr }}=5500 \mu \varepsilon\right)$ and the determination of $\varepsilon_{\text {cftr }}$ can be referred to the corresponding reference (Che et al. [19]).

\subsection{Specimen Preparations}

Fabrication of Circular CFST (C-CFST) specimens can be found in relative reference (Han [9]). Carbon fiber sheets are applied using a hand lay-up method. The longitudinal CFRP is glued firstly, and then the transverse CFRP is glued. The finishing end of a sheet is overlapped to the starting end of the other sheet with an overlapped length of $150 \mathrm{~mm}$.

Table 1. Specimen Labels and Capacities

\begin{tabular}{|c|c|c|c|c|c|c|c|c|c|c|c|}
\hline No. & $\begin{array}{c}\text { Specimens } \\
\text { label }\end{array}$ & $\begin{array}{c}L \\
(\mathrm{~mm})\end{array}$ & $\lambda$ & $\begin{array}{c}m^{\prime} \\
(\text { layer(s) }\end{array}$ & $\eta$ & $\begin{array}{c}m \\
(\text { layer })\end{array}$ & $\xi_{\mathrm{cf}}$ & $\begin{array}{c}D_{\mathrm{s}} \\
(\mathrm{mm})\end{array}$ & $\begin{array}{c}t_{\mathrm{s}} \\
(\mathrm{mm})\end{array}$ & $\xi_{\mathrm{s}}$ & $\begin{array}{c}N_{\mathrm{u}, \mathrm{cr}} \\
(\mathrm{kN})\end{array}$ \\
\hline 1 & CC A-0 & 400 & 12 & 0 & 0 & 1 & 0.13 & 133 & 5 & 1.3 & 2085 \\
\hline 2 & CC A-1 & 400 & 12 & 1 & 0.18 & 1 & 0.13 & 133 & 5 & 1.3 & 2118 \\
\hline 3 & CC A-2 & 400 & 12 & 2 & 0.35 & 1 & 0.13 & 133 & 5 & 1.3 & 2119 \\
\hline 4 & CC A-3 & 400 & 12 & 3 & 0.53 & 1 & 0.13 & 133 & 5 & 1.3 & 2206 \\
\hline 5 & CC B-0 & 530 & 16 & 0 & 0 & 1 & 0.13 & 133 & 5 & 1.3 & 2040 \\
\hline 6 & CC B-1 & 530 & 16 & 1 & 0.18 & 1 & 0.13 & 133 & 5 & 1.3 & 1947 \\
\hline 7 & CC B-2 & 530 & 16 & 2 & 0.35 & 1 & 0.13 & 133 & 5 & 1.3 & 2016 \\
\hline 8 & CC B-3 & 530 & 16 & 3 & 0.53 & 1 & 0.13 & 133 & 5 & 1.3 & 2094 \\
\hline 9 & CC C-0 & 600 & 18 & 0 & 0 & 1 & 0.13 & 133 & 4.5 & 1.3 & 1721 \\
\hline 10 & CC C-1 & 600 & 18 & 1 & 0.18 & 1 & 0.13 & 133 & 4.5 & 1.3 & 1756 \\
\hline 11 & CC C-2 & 600 & 18 & 2 & 0.35 & 1 & 0.13 & 133 & 4.5 & 1.3 & 1831 \\
\hline 12 & CC C-3 & 600 & 18 & 3 & 0.53 & 1 & 0.13 & 133 & 5 & 1.3 & 2090 \\
\hline 13 & CC D-0 & 800 & 24 & 0 & 0 & 1 & 0.13 & 133 & 4.5 & 1.3 & 1682 \\
\hline
\end{tabular}




\begin{tabular}{|c|c|c|c|c|c|c|c|c|c|c|c|}
\hline 14 & CC D-1 & 800 & 24 & 1 & 0.18 & 1 & 0.13 & 133 & 4.5 & 1.3 & 1724 \\
\hline 15 & CC D-2 & 800 & 24 & 2 & 0.35 & 1 & 0.13 & 133 & 4.5 & 1.3 & 1780 \\
\hline 16 & CC D-3 & 800 & 24 & 1 & 0.53 & 1 & 0.13 & 133 & 5 & 1.3 & 2035 \\
\hline 17 & CC E-0 & 1200 & 36 & 2 & 0 & 1 & 0.13 & 133 & 4.5 & 1.3 & 1445 \\
\hline 18 & CC E-1 & 1200 & 36 & 1 & 0.18 & 1 & 0.13 & 133 & 4.5 & 1.3 & 1500 \\
\hline 19 & CC E-2 & 1200 & 36 & 2 & 0.35 & 1 & 0.13 & 133 & 4.5 & 1.3 & 1560 \\
\hline 20 & CC E-3 & 1200 & 36 & 3 & 0.53 & 1 & 0.13 & 133 & 5 & 1.3 & 1914 \\
\hline 21 & $\mathrm{CC} \mathrm{F-0}$ & 1800 & 54 & 0 & 0 & 1 & 0.13 & 133 & 4.5 & 1.3 & 1222 \\
\hline 22 & CC F-1 & 1800 & 54 & 1 & 0.18 & 1 & 0.13 & 133 & 4.5 & 1.3 & 1281 \\
\hline 23 & $\mathrm{CC} \mathrm{F-2}$ & 1800 & 54 & 2 & 0.35 & 1 & 0.13 & 133 & 4.5 & 1.3 & 1358 \\
\hline 24 & $\mathrm{CC} \mathrm{F-3}$ & 1800 & 54 & 3 & 0.53 & 1 & 0.13 & 133 & 5 & 1.3 & 1704 \\
\hline 25 & CC G-0 & 2400 & 72 & 0 & 0 & 1 & 0.13 & 133 & 5 & 1.3 & 1387 \\
\hline 26 & $\mathrm{CC} \mathrm{G-1}$ & 2400 & 72 & 1 & 0.18 & 1 & 0.13 & 133 & 5 & 1.3 & 1409 \\
\hline 27 & CC G-2 & 2400 & 72 & 2 & 0.35 & 1 & 0.13 & 133 & 5 & 1.3 & 1428 \\
\hline 28 & $\mathrm{CC} \mathrm{G-3}$ & 2400 & 72 & 3 & 0.53 & 1 & 0.13 & 133 & 5 & 1.3 & 1613 \\
\hline 29 & $\mathrm{CC} \mathrm{H}-0$ & 3000 & 90 & 0 & 0 & 1 & 0.13 & 133 & 5 & 1.3 & 1296 \\
\hline 30 & $\mathrm{CC} \mathrm{H}-1$ & 3000 & 90 & 1 & 0.18 & 1 & 0.13 & 133 & 5 & 1.3 & 1174 \\
\hline 31 & CC H-2 & 3000 & 90 & 2 & 0.35 & 1 & 0.13 & 133 & 5 & 1.3 & 1243 \\
\hline 32 & $\mathrm{CCH}-3$ & 3000 & 90 & 3 & 0.53 & 1 & 0.13 & 133 & 5 & 1.3 & 1467 \\
\hline
\end{tabular}

\subsection{Material Properties}

Seamless steel tube is in the columns. Tensile tests on steel coupons cut from the original steel tubes are conducted. The measured properties of the steel tubes obtained from these tests are given in Table 2, where $E_{\mathrm{s}}$ and $v_{\mathrm{s}}$ are the elasticity modulus and the Poisson' ratio of the steel tube, respectively.

Table 2. Material Properties of Steel Tube

\begin{tabular}{|c|c|c|c|}
\hline$t_{\mathrm{s}}(\mathrm{mm})$ & $E_{\mathrm{s}}(\mathrm{GPa})$ & $f_{\mathrm{y}}(\mathrm{MPa})$ & $v_{\mathrm{s}}$ \\
\hline 4.5 & 206 & 333 & 0.27 \\
\hline 5 & 204 & 303 & 0.26 \\
\hline
\end{tabular}

The in-filled concrete of all the specimens has same material property. In the concrete mixture, Portland cement is used, and the fine aggregate is silica-based sand. The course aggregate is limestone with a largest size of $20 \mathrm{~mm}$, and $1 \%$ (in weight) water reducing agent is added. The mixture proportions of the concrete are summarized in Table 3.

Table 3. Mixture Proportions of Concrete $\left(\mathrm{kg} \cdot \mathrm{m}^{-3}\right)$

\begin{tabular}{|c|c|c|c|}
\hline Cement & Water & Sand & Course aggregate \\
\hline 485 & 150 & 703 & 1062 \\
\hline
\end{tabular}

To determine the compressive strength of the in-filled concrete, six cubes with a side length of 150 $\mathrm{mm}$ are cast and cured in conditions similar to those of the related specimens. The averaged cubic 
strength $\left(f_{\text {cu }}\right)$ at 28 days is $48.8 \mathrm{MPa}$. At the testing time (six months later due to the delay of the test program), the cubic strength of $57.4 \mathrm{MPa}$ is achieved and is adopted in later FE simulation and calculation. Elasticity modulus of the concrete $\left(E_{\mathrm{c}}\right)$ is $35.9 \mathrm{GPa}$.

Carbon fiber sheet used in the specimens is a kind of one-way sheet, and the properties of the CFRP determined from tensile tests of six flat coupons are given in Table 4 , in which $f_{\text {cf }}{ }^{\prime}, \delta_{\text {cf }}$ and $w_{\mathrm{cf}}$ are the tensile strength, the elongation percentage and the density of the carbon fiber sheet, and $t_{\mathrm{cf}}$ is the thickness of one-layer carbon fiber sheet.

Table 4. Main Technical Properties of Carbon Fiber Sheets

\begin{tabular}{|c|c|c|c|c|c|}
\hline Model number & $f_{\mathrm{cf}}{ }^{\prime}(\mathrm{GPa})$ & $E_{\mathrm{cf}}(\mathrm{GPa})$ & $\delta_{\mathrm{cf}}(\%)$ & $w_{\mathrm{cf}}\left(\mathrm{g} \cdot \mathrm{m}^{-2}\right)$ & $t_{\mathrm{cf}}(\mathrm{mm})$ \\
\hline $\mathrm{C} 200 / 200$ & 4.83 & 230 & 2.1 & 200 & 0.111 \\
\hline
\end{tabular}

It should be pointed out that the rupture strain of the coupon CFRP is $21000 \mu \varepsilon$ while the rupture strains of the longitudinal CFRP $\varepsilon_{\text {cflr }}=10000 \mu \varepsilon$ and that of the transverse CFRP $\varepsilon_{\text {cftr }}=5500 \mu \varepsilon$. Such difference is possibly caused by different curvatures at CFPR positions, and the relative research (Yu et al. [37]) provided similar conclusion.

JGN-C, a typical kind of epoxy resin, which is produced by Building Science Research Institute of Liaoning Province of China and is used for building structures, is selected for adhering the CFRP to the steel tube. Another kind of epoxy resin, JGN-P, is used for gluing CFRPs together.

\subsection{Test Setup and Instrumentation}

The experimental test is carried out in the Structural Laboratory of Shenyang Jianzhu University, P. R. China. The critical buckling load of the specimen is predicted before the specimen is loaded: the transverse and the longitudinal CFRPs are simplified to equivalent steel tube, and then the critical buckling load can be calculated by using corresponding equations of C-CFST columns (Han et al. [11]). However, the equivalent steel tube besides longitudinal CFRP is not considered in calculating the confinement factor of the steel tube $\xi_{\mathrm{s}}$.

The test setup is shown in Figure 3. The specimen is pinned at both ends. A instrument with a loading capacity of $5,000 \mathrm{kN}$ is used to apply axial compressive load $N$. The load is applied in many loading steps. In the elastic stage, each loading step is $1 / 10$ of the estimated critical buckling load. When the applied load is about $60 \%$ of the estimated critical buckling load, the magnitude of the loading step is reduced to $1 / 15-1 / 20$ of the estimated critical buckling load. After the deflection at the mid-height exceeds $L / 50$, displacement control is used till the deflection at the mid-height reaches about $L / 25$. The interval between two continuous loading steps is maintained for about 2 to $3 \mathrm{~min}$.

As shown in Figure 3, 3-5 Linear Variable Differential Transformers (LVDTs) are placed in the bending plane with equal distance in the height direction according to different heights of the specimens to measure the lateral deflection. Simultaneously, two LVDTs are used to measure the longitudinal compression of the specimens. Overall, 11 strain gauges are glued on the surfaces of each steel tube and on the CFRP at the mid-height of the specimens respectively, as shown in Figure 4, where points 1-7 are the locations for measuring the longitudinal strains and points 1, 3, 5 and 8 are the locations for measuring the transverse strains. 
The data is captured by Data Acquisition System U-CAM-70A, and the $N-u_{\mathrm{m}}$ curve is achieved simultaneously.

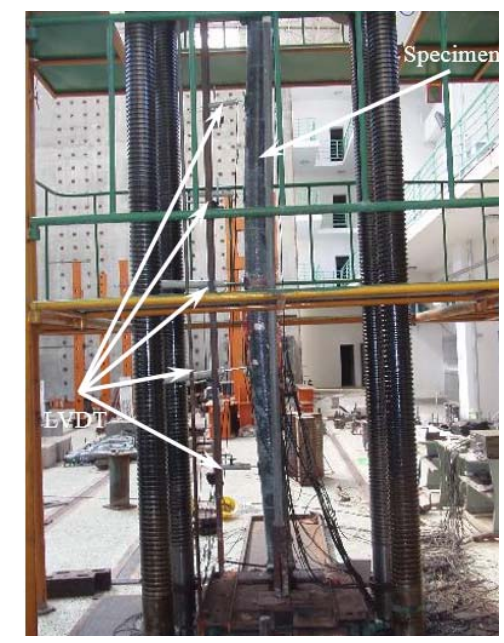

Figure 3. Test Arrangement (Specimen CC H-1)

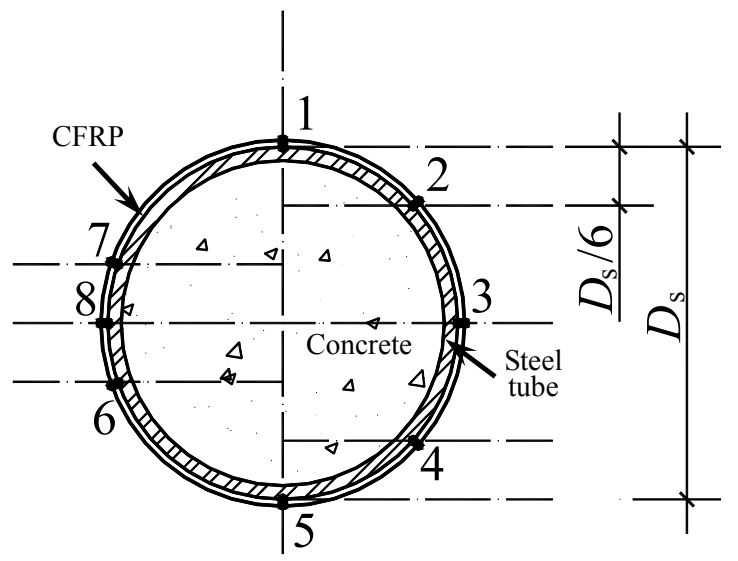

Figure 4. Location of Strain Gauges

\subsection{Test Observations and Failure Modes}

The failure of the specimens is mainly determined by the slenderness ratio $(\lambda)$. For specimens with small $\lambda$, transverse CFRP located in longitudinal compressive region at the mid-height begins to fracture at a loading about $0.85 N_{\mathrm{u}, \mathrm{t}}^{\mathrm{t}}$. With the increase of the applied load, the amount of fractured transverse CFFPs becomes bigger (as shown in Figure 5 (a)) till the applied load reaches $N_{\mathrm{u}, \mathrm{t} r}^{\mathrm{t}}$. Longitudinal CFRP located in longitudinal tensile region at the mid-height is not fractured in general, and the specimens have local outward buckling (as shown in Figure 5 (a)) which indicates a symbol of strength failure. For specimens with large $\lambda$, transverse CFRP located in longitudinal compressive region at the mid-height begins to fracture after $N_{\mathrm{u}, \mathrm{tr}}^{\mathrm{t}}$. With the increase of the deflection, the longitudinal CFRP located in longitudinal tensile region at the mid-height begins to fracture (as shown in Figure 5 (b)). Finally, the specimens fail and the steel tube does not buckle outward and forms an instability failure. All specimens after failure are shown in Figure 6.

The CFRP-steel composite tubes are cut off after test. As shown in Figure 7, it is found that the concrete could be divided into both tensile and compressive regions. For specimens with small $\lambda$, 
the failure of the concrete is severe, and the concrete in the compressive region is crushed (as shown in Figure 7 (a)). In the tensile region, the concrete crack has a big width, and the distance between any two adjacent cracks is small (as shown in Figure 7 (b)). For specimens with large $\lambda$, the concrete failure is not severe, and thus the concrete in compressive region is almost not damaged (as shown in Figure 7 (c)). The crack in tensile region has a narrow width, and the distance between any two adjacent cracks is bigger (as shown in Figure 7 (d)).

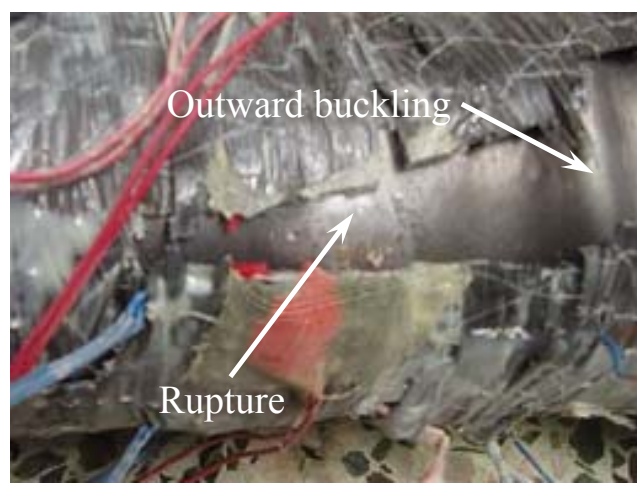

(a) Transverse CFRP

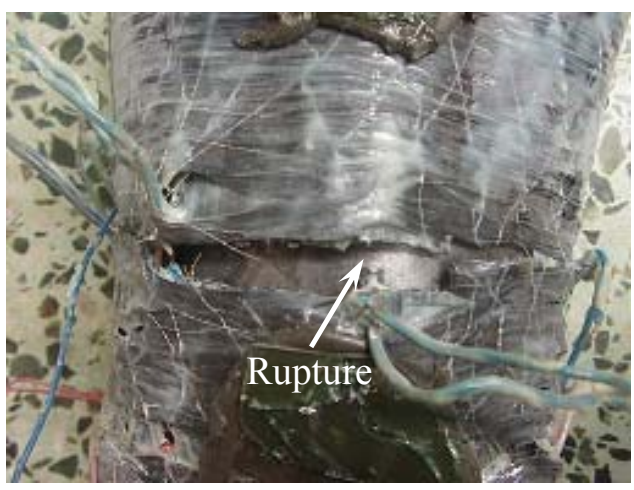

(b) Longitudinal CFRP

Figure 5. Rupture of CFRPs and Local Buckling

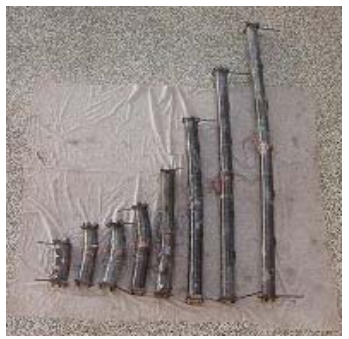

(a) $m^{\prime}=0 \quad$ Specimens

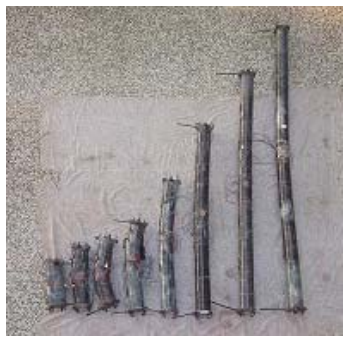

(b) $m^{\prime}=1$ Specimens

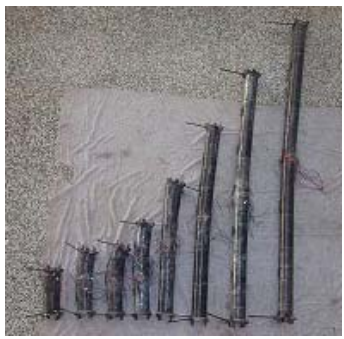

(c) $m^{\prime}=2$ specimens

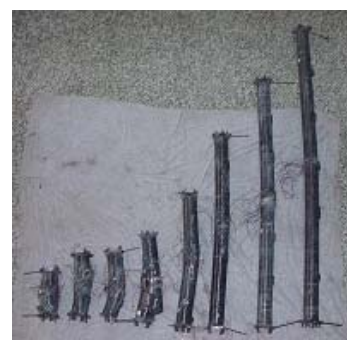

(d) $m^{\prime}=3$ Specimens

Figure 6. All Specimens after Testing

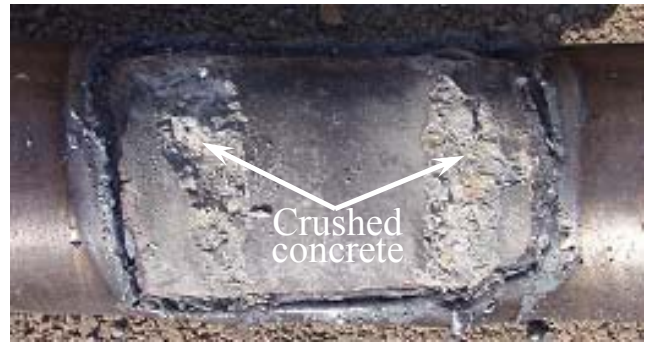

(a) Compressed Concrete of Specimen CC C-1

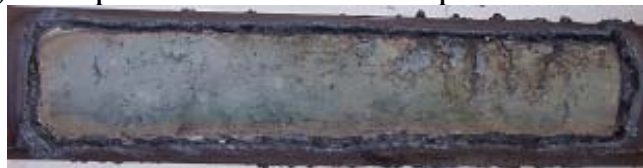

(c) Compressed Concrete of Specimen CC H-2

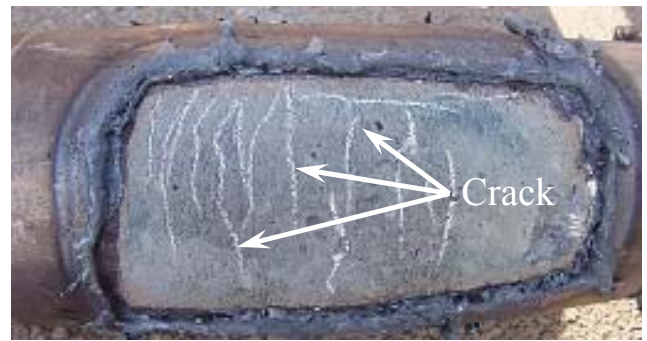

(b) Tensioned Concrete of Specimen CC C-1

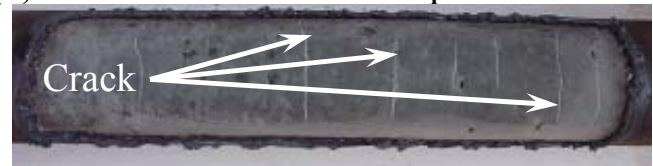

(d) Tensioned Concrete of Specimen CC H-2

Figure 7. Failure Modes of Concrete

\subsection{Test Results and Analysis}

\subsubsection{Tested $N$ - $u_{\mathrm{m}}$ curves}

Figure 8 shows the $N-u_{\mathrm{m}}$ curves of the specimens, and it can be found that these $N-u_{\mathrm{m}}$ curves 
have the following characteristics: the curves develop linearly in initial loading stage, and this period belongs to an elastic stage. The following stage is elasto-plastic stage in which the developing rate of $u_{\mathrm{m}}$ is apparently faster than that of $N$. The curves begin to drop after $N_{\mathrm{u}, \mathrm{cr}}^{\mathrm{t}}$, and in this stage the increase of $u_{\mathrm{m}}$ is much faster while the decrease of $N$ is gradual.

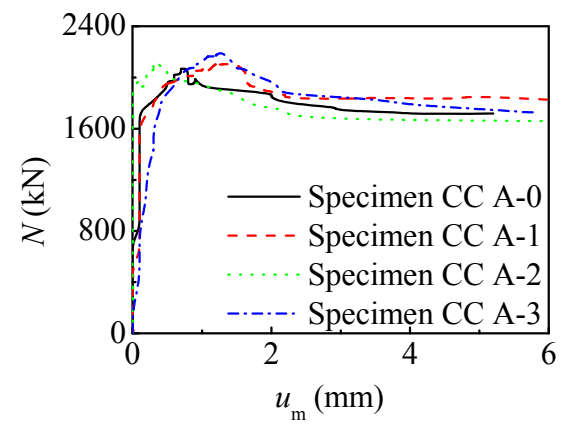

(a) Specimens of $\lambda=12$

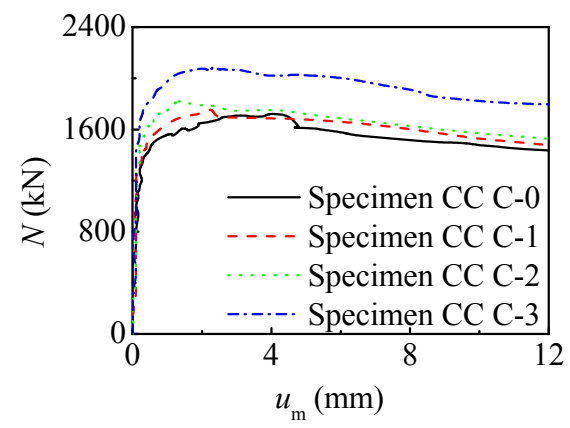

(c) Specimens of $\lambda=18$

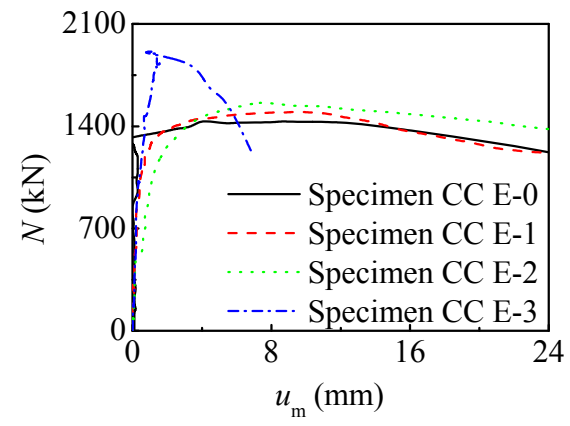

(e) Specimens of $\lambda=36$

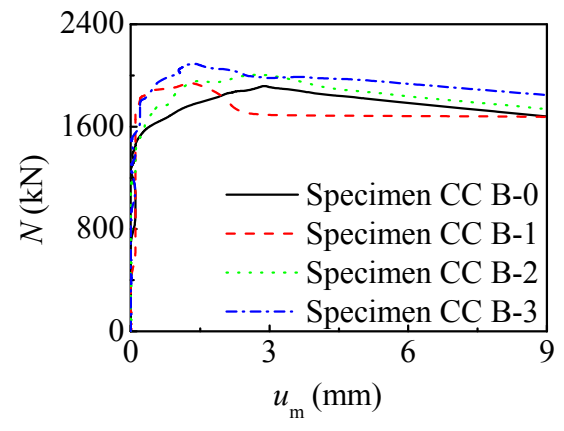

(b) Specimens of $\lambda=16$

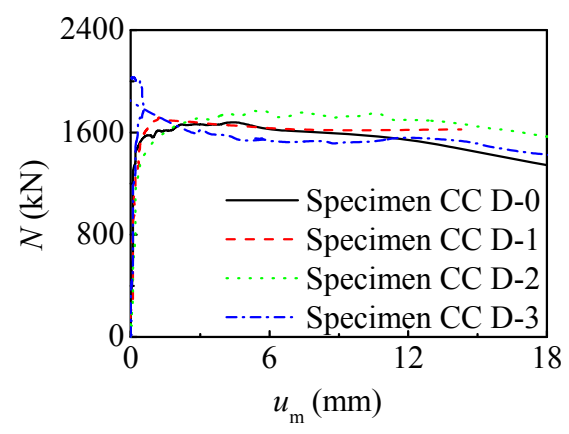

(d) Specimens of $\lambda=24$

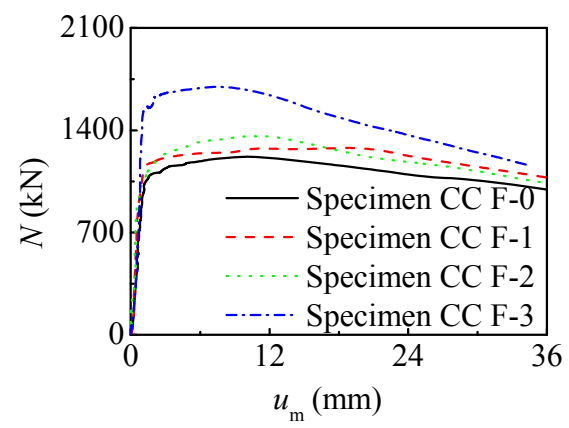

(f) Specimens of $\lambda=54$ 


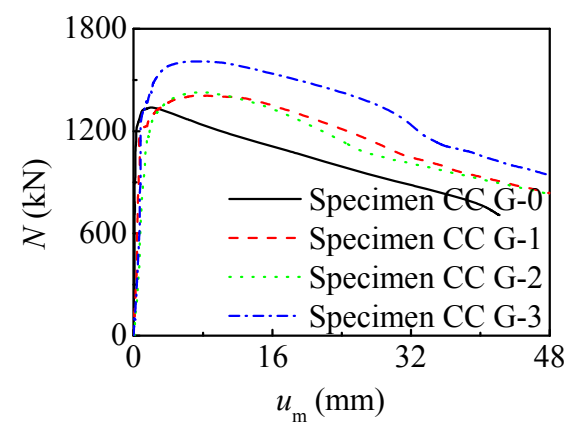

(g) Specimens of $\lambda=72$

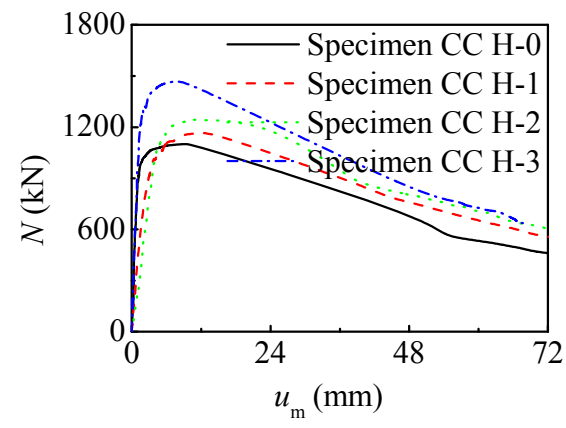

(h) Specimens of $\lambda=90$

Figure 8. Tested $N-u_{\mathrm{m}}$ Curves

\subsubsection{Tested $N$ - $\Delta$ curves}

Figure 9 shows the $N-\Delta$ curves of the specimens, where $\Delta$ is the axial shortening of the specimen.

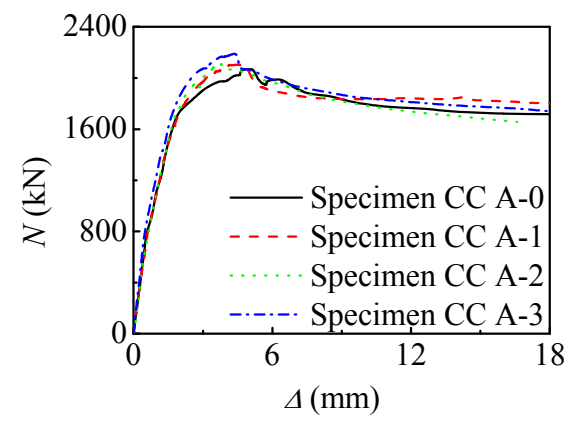

(a) Specimens of $\lambda=12$

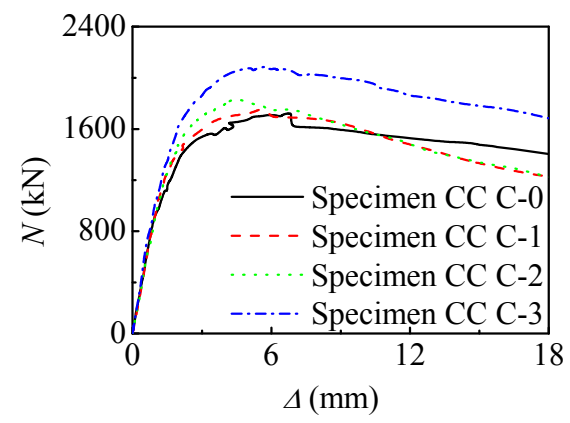

(c) Specimens of $\lambda=18$

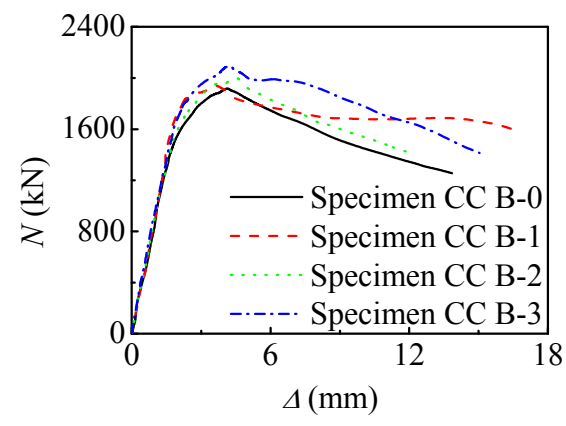

(b) Specimens of $\lambda=16$

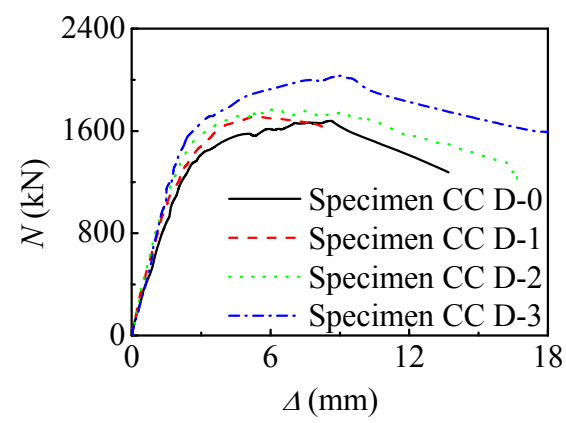

(d) Specimens of $\lambda=24$ 


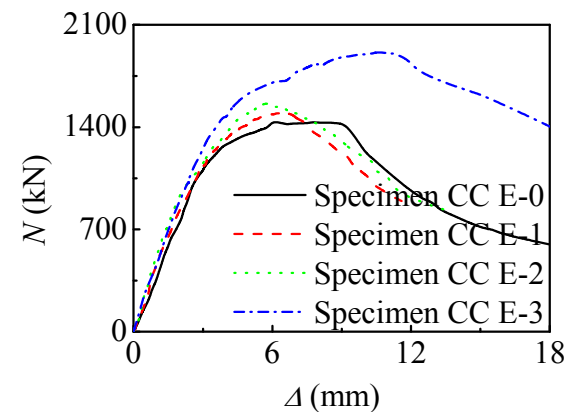

(e) Specimens of $\lambda=36$

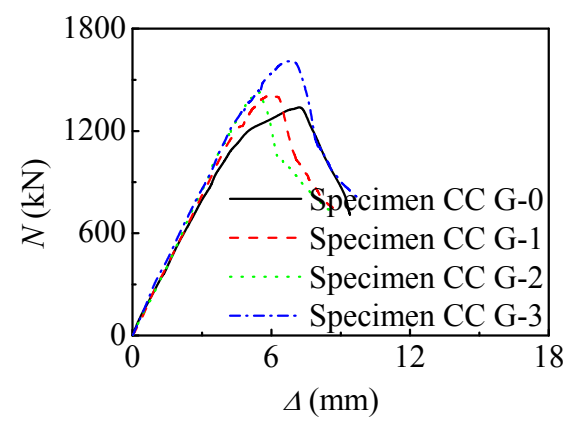

(g) Specimens of $\lambda=72$

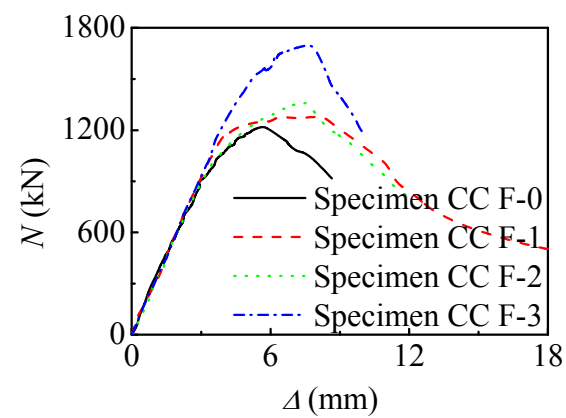

(f) Specimens of $\lambda=54$

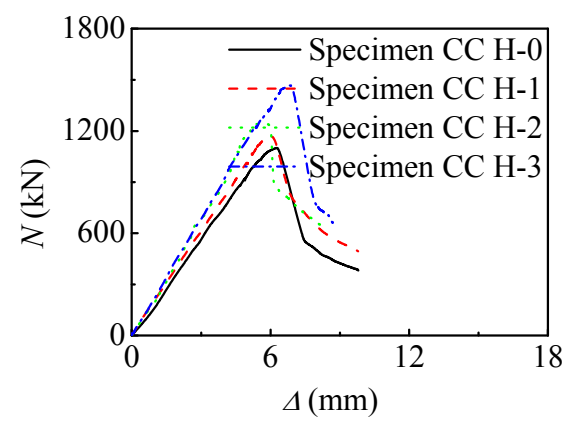

(h) Specimens of $\lambda=90$

Figure 9. Tested $N-\Delta$ Curves

\subsubsection{Comparison between longitudinal Strain and Transverse Strain}

Figure 10 shows comparison between $\varepsilon_{\mathrm{sl}}$ (longitudinal strain of the steel tube) and $\varepsilon_{\mathrm{st}}$ (transverse strain of the steel tube) at point 1 and point 5 for specimen CC E-2, where $\varepsilon_{\mathrm{s}}$ is the strain of the steel tube. The signs of $\varepsilon_{\mathrm{sl}}$ and $\varepsilon_{\text {st }}$ at same point are different: it is negative in longitudinal direction while positive in transverse direction and vice versa. Studies on CF-CFRP-ST stub column (Che et al. [19]; Wang and Shao [34]) and CF-CFRP-ST flexural member (Wang and Shao [28]; Wang et al. [36]) provided same conclusions. It can also be found that point 1 on the steel tube is under tension longitudinally and under compression transversely after $N_{\mathrm{u}, \mathrm{t} r}^{\mathrm{t}}$, which makes it clear that this point together with the around steel tube has no confinement to concrete, and the reason may be listed as follow: the nearby concrete is also in a tensile state when the steel tube is under tension in longitudinal direction, and thus it does not need transverse confinement provided from steel tube. The transverse strain of the steel tube is under compression due to the corresponding tension in longitudinal direction.

\subsubsection{Plane Section Assumption}

Figure 11 shows the distribution of $\varepsilon_{\mathrm{sl}}$ over the depth on the cross-section of the specimen with a slenderness ratio $\lambda=24$. As shown in Figure 11, the distribution of $\varepsilon_{\mathrm{sl}}$ is basically satisfied with the plane section assumption. Studies on CF-CFRP-ST flexural member (Wang and Shao [28]; Wang et al. [36]) provided same conclusions. 


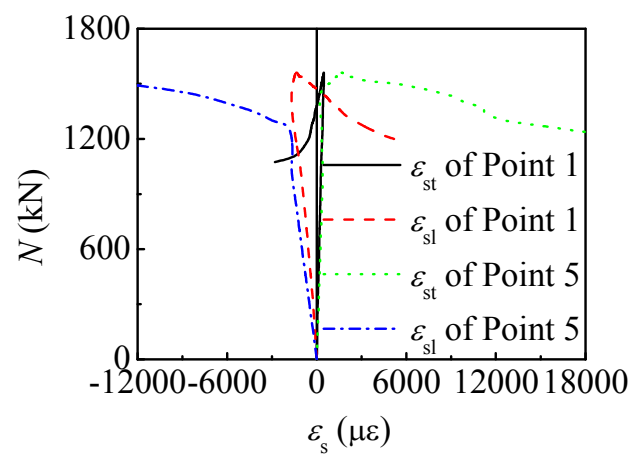

Figure 10. Comparisons between $\varepsilon_{\mathrm{sl}}$ and $\varepsilon_{\mathrm{st}}$ of Point 1 and Point 5 for Specimen CC E-2

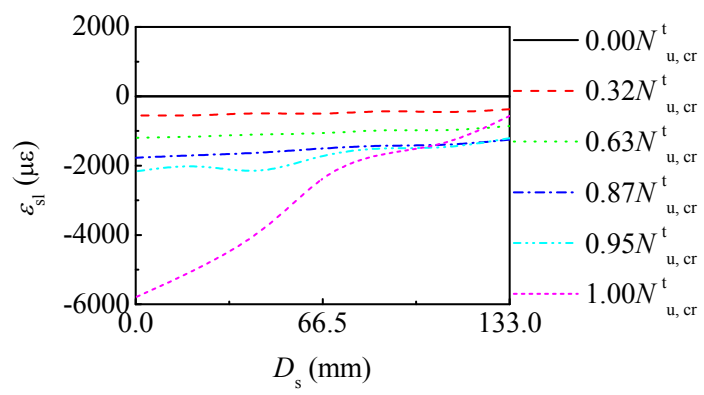

(a) Specimen CC F-0

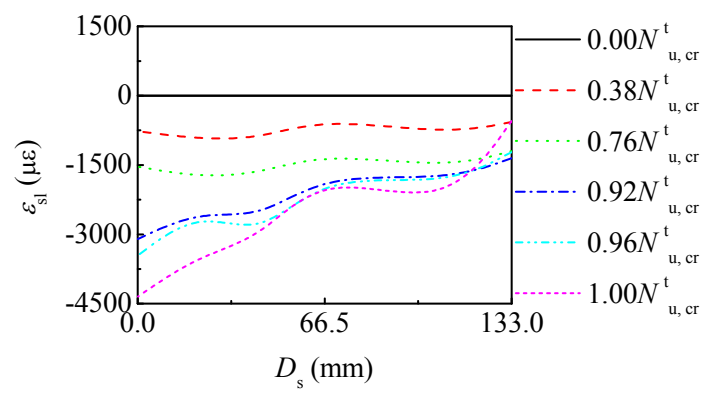

(c) Specimen CC F-2

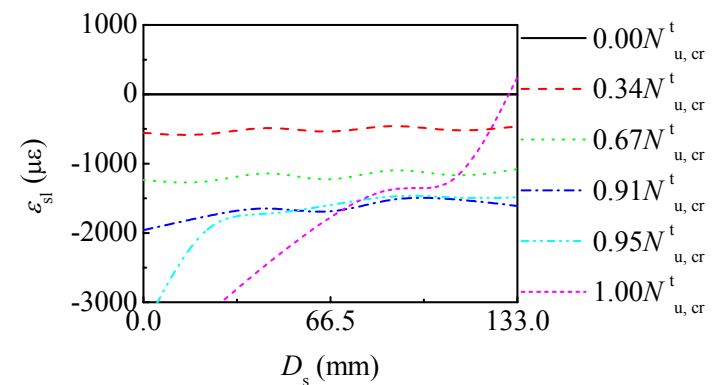

(b) Specimen CC F-1

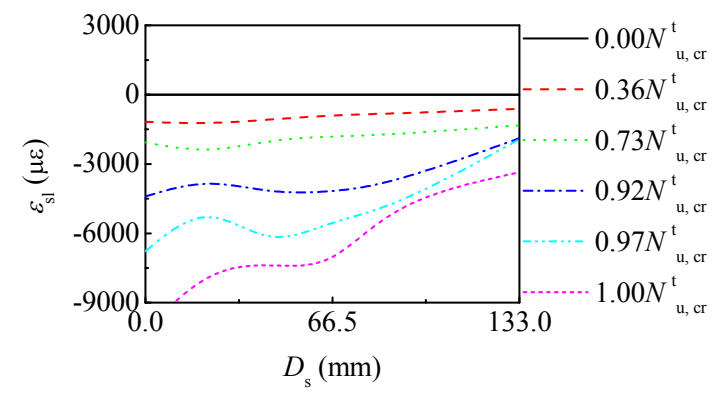

(d) Specimen CC F-3

Figure 11. Distribution of $\varepsilon_{\mathrm{sl}}$ over Depth of Cross-Section for $\lambda=24$ Specimens

\section{FE SIMULATION}

\subsection{Stress-Strain Relationship of Materials}

A 5-stage stress-strain relationship of steel material (Han et al. [10]) is used in the FE simulation. The constitutive relationships of the concrete confined by circular CFRP-steel tube under compression as well as under tension (Che et al. [19]) are adopted. The CFRP is assumed to be subjected to tension only, and the stresses in other directions are assumed to be $0.001 \mathrm{MPa}$. Before fracture, the stress-strain relationship is in accordance with Hooke's Law

$\sigma_{\mathrm{cf}}=E_{\mathrm{cf}} \varepsilon_{\mathrm{cf}}$ 
where $\sigma_{\mathrm{cf}}$ and $\varepsilon_{\mathrm{cf}}$ are the stress and the strain of CFRP, respectively. When longitudinal CFRP reaches its rupture strain $\left(\varepsilon_{\text {cflr }}\right)$, it loses longitudinal strengthening effect to the specimens. When transverse CFRP reaches its rupture strain $\left(\varepsilon_{\mathrm{cftr}}\right)$, it loses transverse confinement to the steel tube.

\section{2 $\quad$ FE Model}

\subsubsection{Element type selection and mesh discritization}

The adopted element in the mesh of the steel tube is shell element S4 with full integration. Simpson integration with 9 integrating points in the shell thickness direction is used. For the mesh of the concrete, 3-D brick elements C3D8R with reduced integration is used. Membrane element M3D4 with 4-nodes is used for modelling CFRP. The convergent analysis is carried out by using refined mesh in finite element analysis, details can be found in Ref. (Che et al. [19]).

\subsubsection{Interface model}

Hard contact is used for contact interface between the steel tube and the concrete, i.e., the pressure perpendicular to the contact surfaces $(p)$ can be transferred completely between the two surfaces. The tangential force between the steel tube and the concrete is simulated by using Columb model, i.e., shear force can be transferred between two contact surfaces. In the tangential direction of the contact surfaces between the end plate and the concrete, there is no slipping, and hard contact assumption is used in normal direction of the contact surfaces.

Figure 12 shows the comparison of the strains between the steel tube and the CFRP, where, $\varepsilon_{1}$ and $\varepsilon_{\mathrm{t}}$ are the longitudinal strain and the transverse strain respectively, and $\varepsilon_{\mathrm{cfl}}$ and $\varepsilon_{\mathrm{cft}}$ are the strains of the longitudinal CFRP and the transverse CFRP, respectively. As shown in Figure 12, $\varepsilon_{\mathrm{sl}}$

and $\varepsilon_{\text {cfl }}$, as well as $\varepsilon_{\text {st }}$ and $\varepsilon_{\text {cft }}$, are approximately same. Additionally, after cutting the CFRP-steel tubes into halves after the tests, it is found that the adherence between the CFRP and the steel tube is still intact except at the region where CFRP ruptured. All above indicate that the steel tubes and the CFRP could cooperate well in both longitudinal and transverse directions. Studies on CF-CFRP-ST stub column (Che et al. [19]; Wang and Shao [34]) and CF-CFRP-ST flexural member (Wang and Shao [28]; Wang et al. [36]) provided same conclusions.

According to the above test results, the CFRP is bound to the steel tube in the finite element model, and it is assumed that no slip exists between the CFRP and the steel tube. Same nodal freedoms are used for the contact elements between the CFRP and the steel tube.

\subsubsection{Boundary conditions}

Boundary conditions (as shown in Figure 13) are simulated as the same situations in the experimental process. According to the symmetry of both the geometry and the boundary condition, $1 / 4$ of the entire model is selected for FE analysis. On the symmetrical plane of the model, symmetrical constraints are applied. At one end, the displacements in $x$-, $y$ - and $z$-directions are all restrained. At the other end, line loading is applied (considering initial eccentricity of $L / 1000$ ). Increment iteration method is used to solve the problem in which controlled displacement loading method is used. 


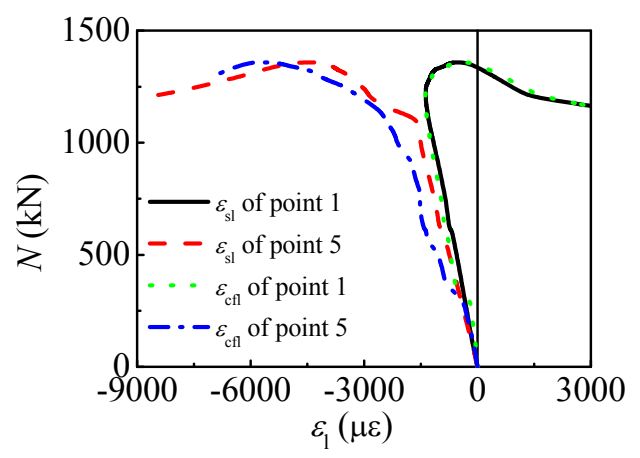

(a) $N-\varepsilon_{1}$ Curves

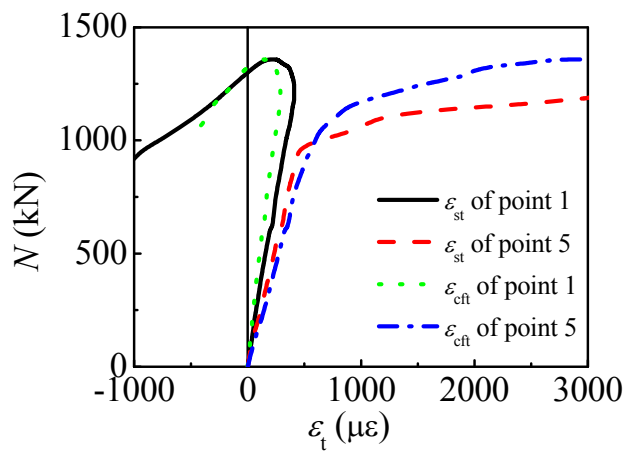

(b) $N-\varepsilon_{\mathrm{t}}$ Curves

Figure 12. Comparisons between $\varepsilon_{\mathrm{s}}$ and $\varepsilon_{\mathrm{cf}}$ for Specimen CC F-2

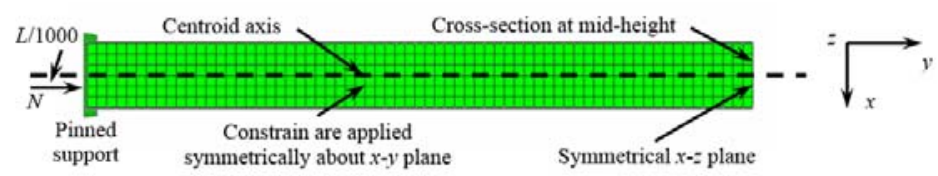

(a) Longitudinal direction

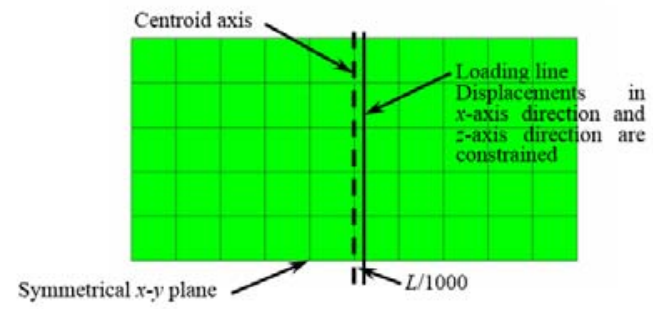

(b) End plate

Figure 13. Boundary Conditions

\subsection{FE Results}

\subsubsection{Failure modes}

To verify the reliability of the above presented FE method, overall 32 axially compressed C-CF-CFRP-ST columns are analyzed by using ABAQUS software. Figure 14 shows the deformation modes of the specimen in the test and in FE simulation. From Figure 14, it can be 
found that the simulated results agree reasonably well with the experimental results.

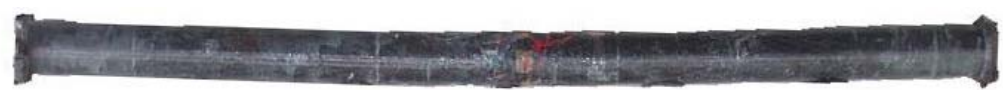

(a) Tested Result

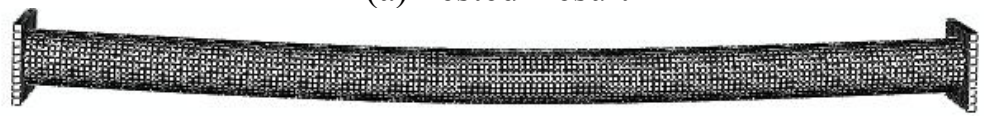

(b) Simulated Result

Figure 14. Deformation Modes

\subsubsection{N-um curves}

The FE $N-u_{\mathrm{m}}$ curves together with the measured results of several specimens are plotted in Figure 15. The FE results agree reasonably well with the experimental results. The average ratio of the critical buckling load between the FE and the experimental results $\left(N_{\mathrm{u}, \text { cr }}^{\mathrm{t}}\right)$ is 0.848 , and the COV is 0.092. The simulated results for the specimens with large slenderness are relatively smaller, and it is mainly caused by the following reason: The initial eccentricities for all the tested specimen are roughly equal in the experiment. However, such initial eccentricity is prescribed to be $L / 1000$, which implies that the specimen with a larger slenderness has a bigger initial eccentricity and hence it has a lower simulated result.

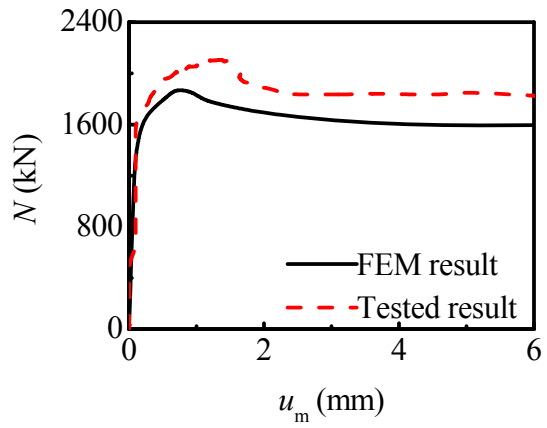

(a) Specimen CC A-1

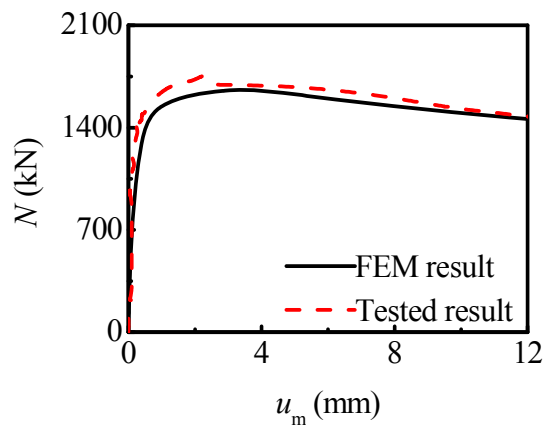

(c) Specimen CC C-1

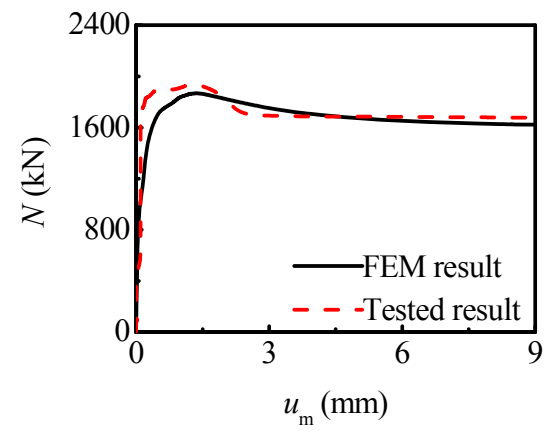

(b) Specimen CC B-1

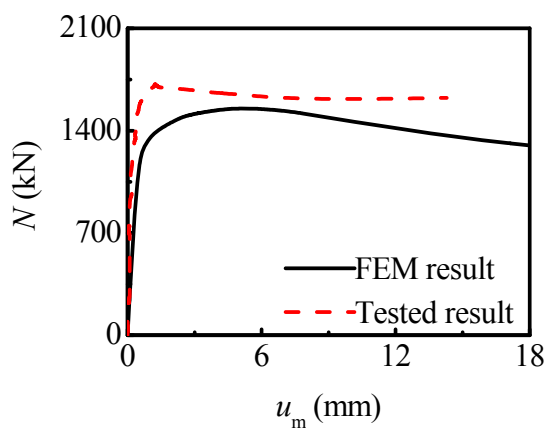

(d) Specimen CC D-1 


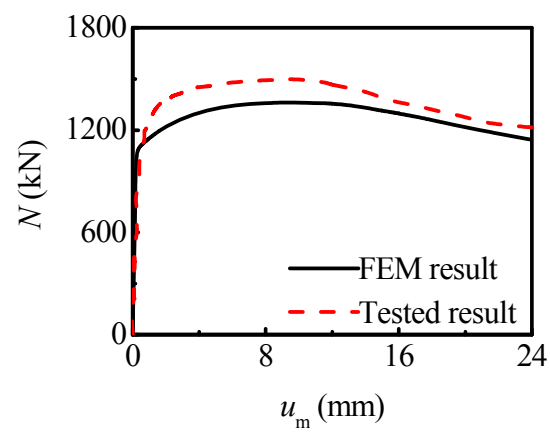

(e) Specimen CC E-1

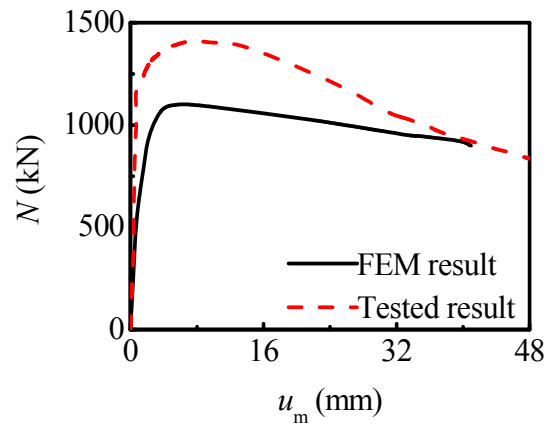

(g) Specimen CC G-1

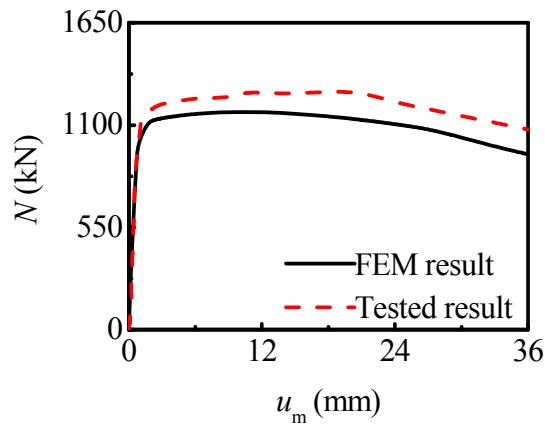

(f) Specimen CC F-1

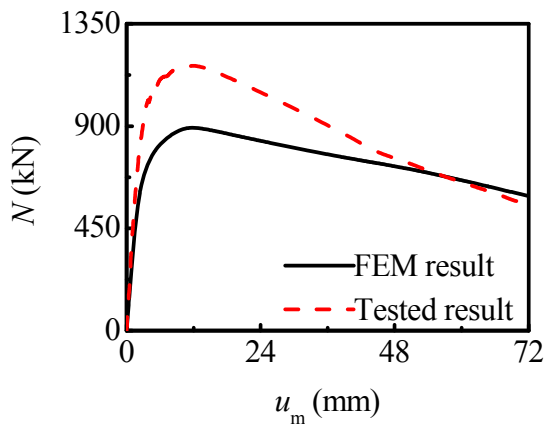

(h) Specimen CC H-1

Figure 15. Comparisons of $N-u_{\mathrm{m}}$ Curves between FEM Result and Tested Result for Several Specimens

\subsection{3 $N$ - $\Delta$ curves}

The FE $N-\Delta$ curves together with the measured results of several specimens are also given in Figure 16. The FE results agree reasonably well with the experimental results.

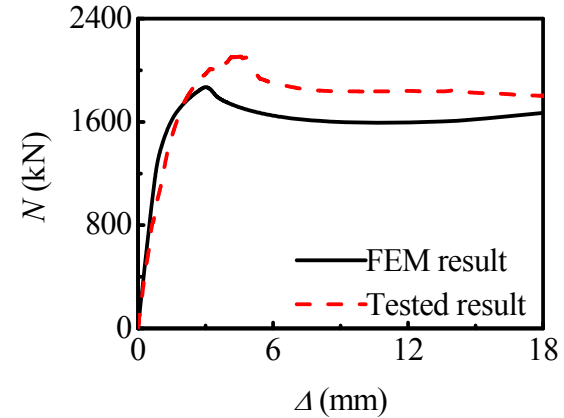

(a) Specimen CC A-1

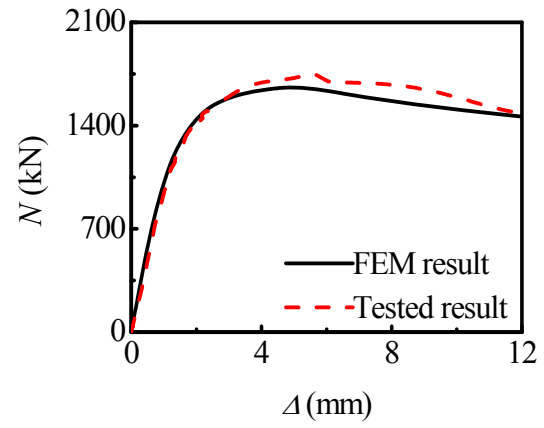

(c) Specimen CC C-1

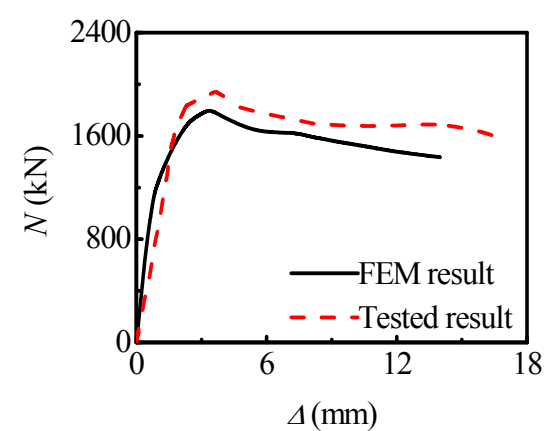

(b) Specimen CC B-1

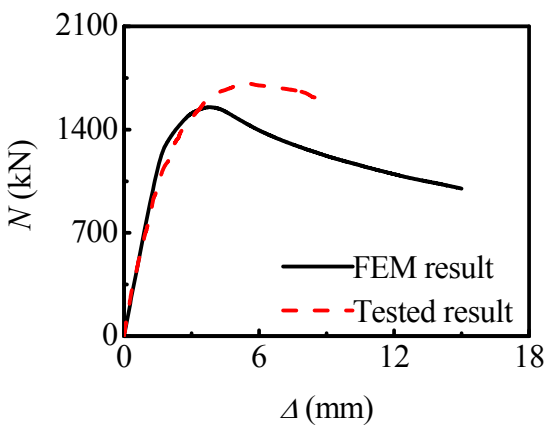

(d) Specimen CC D-1 


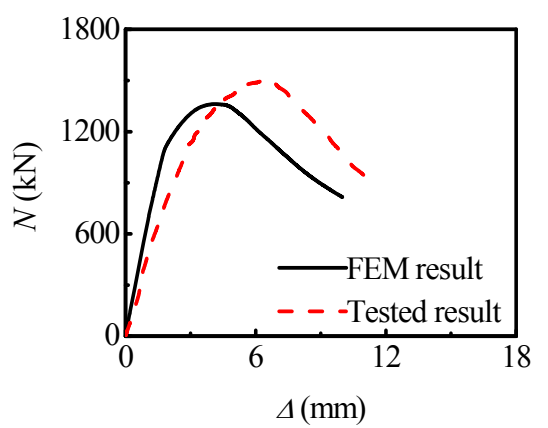

(e) Specimen CC E-1

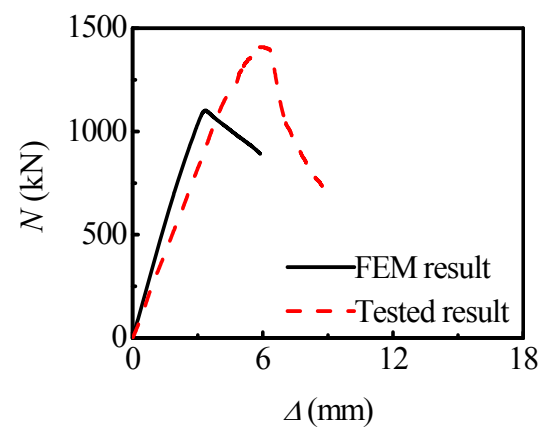

(g) Specimen CC G-1

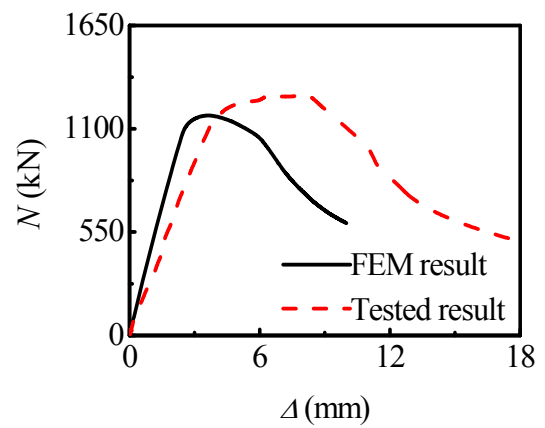

(f) Specimen CC F-1

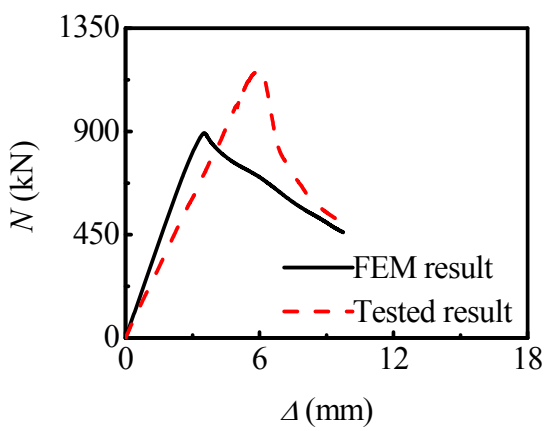

(h) Specimen CC H-1

Figure 16. Comparisons of $N$ - $\Delta$ Curves between FEM Result and

Tested Result for Several Specimens

\subsubsection{N- $\varepsilon_{\mathrm{s}}$ curves}

The comparison of the strains in the steel tube of specimen CC E-1 is shown in Figure 17. Experimental and FE results are denoted in thin line and in thick line respectively, and the simulated results of the tube strains agree well with the experimental results.

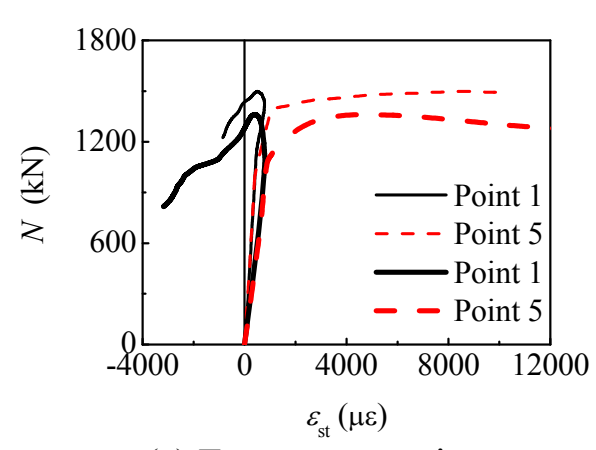

(a) Transverse strains

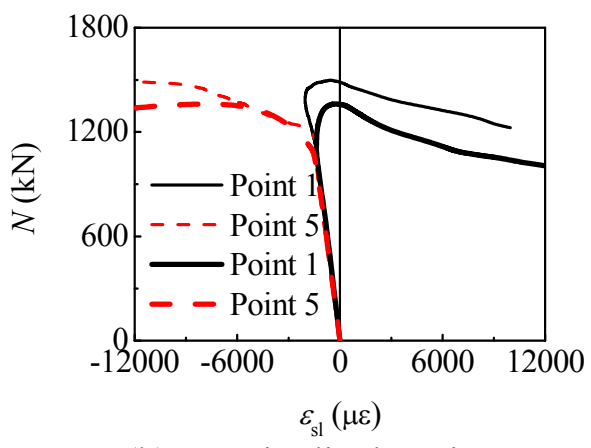

(b) Longitudinal strains

Figure 17. Comparison between Steel Tube Strains of Specimen CC E-1

\section{THEORETICAL ANALYSIS}

On the basis of the above model and approach, a large number of parametric analyses show that the validity range of the models in the presented approach is: $f_{\mathrm{y}}=200-400 \mathrm{MPa}, f_{\mathrm{cu}}=30-120 \mathrm{MPa}$, $\xi_{\mathrm{s}}=0.2-4, \xi_{\mathrm{cf}}=0-0.6, \eta=0-0.9$. In the above validity range, a typical model is selected to carry out theoretical analysis, and the details of the typical model are listed as follows: 
$D_{\mathrm{s}}=400 \mathrm{~mm}, t_{\mathrm{s}}=9.3 \mathrm{~mm}, f_{\mathrm{y}}=345 \mathrm{MPa}, f_{\mathrm{cu}}=60 \mathrm{MPa}, \lambda=80, \xi_{\mathrm{cf}}=0.0383, \eta=0.163$, elasticity Poisson's ratio of concrete $v_{\mathrm{c}}=0.2, E_{\mathrm{c}}=4700 \sqrt{f_{\mathrm{c}}{ }^{\prime}}$ (where $f_{\mathrm{c}}{ }^{\prime}$ is the compressive strength of cylinder concrete specimens and its unit is in MPa). Five typical points as shown in Figure 18 are selected for further analysis. In Figure 18, the load is proportional to the lateral deflection before point 1 , and the stress of the steel tube reaches its proportional limit at point 1 . Plastic region occurs on the cross-section at the mid-height between point 1 and point 2 , and the critical buckling load is reached at point 2 . Area of the plastic region increases gradually after point 2 , and the transverse CFRP on the longitudinally compressive region ruptures at point 3 . The longitudinal CFRP on the longitudinally tensile region ruptures at point 4 . Deflection at the mid-height is very large (about $L / 25$ ) at point 5 .

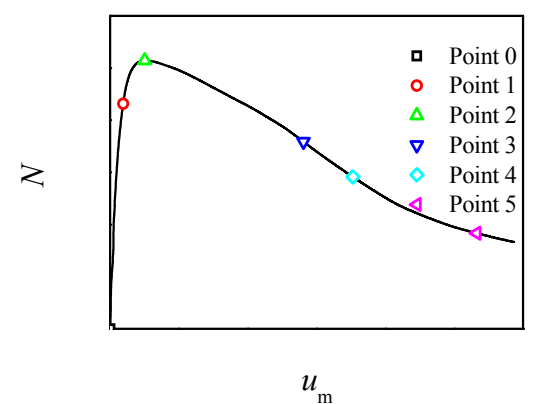

Figure 18. Typical $N-u_{\mathrm{m}}$ Curve of Axially Compressed C-CF-CFRP-ST Columns with Moderate Slenderness Ratio

\subsection{Stress analysis}

\subsubsection{Stress in concrete}

Figure 19 illustrates the distribution of the longitudinal stress in the concrete on the cross-section at the mid-height for axially compressed C-CF-CFRP-ST column with moderate slenderness ratio. All the cross-section of the concrete is found to be under compression before the critical buckling load is reached. After the critical buckling load, tensile region initiates on the concrete section. With the increasing deflection at the mid-height of the column, the area of the compressive region reduces and the area of the tensile region enlarges continuously.

Figure 20 shows the distribution of the longitudinal stress in the concrete in axial direction. It can be found that such distribution is not uniform and the stresses of the concrete in the compressive region on the cross-section at the mid-height increase gradually.

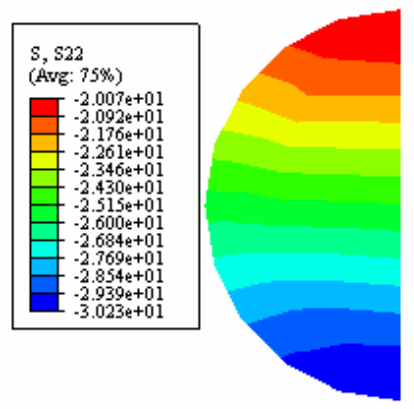

(a) Point 1
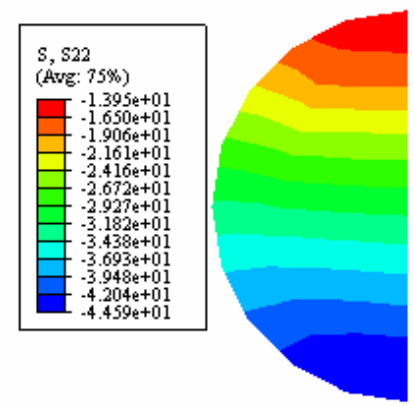

(b) Point 2
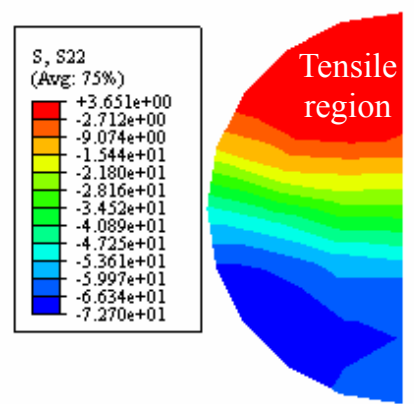

(c) Point 3 


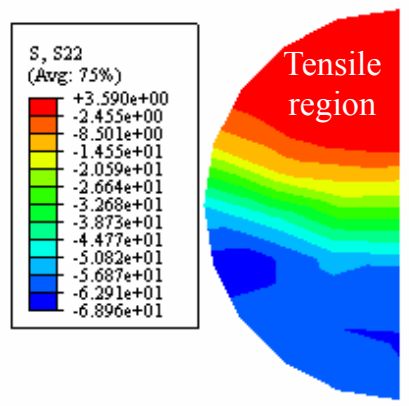

(d) Point 4

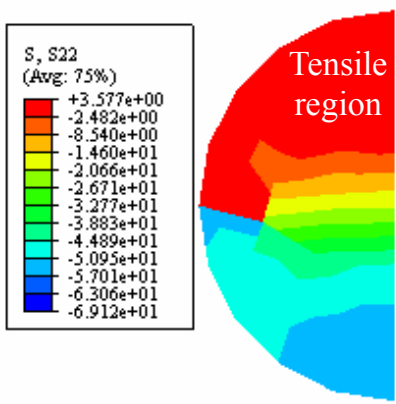

(e) Point 5

Figure 19. Distribution of Longitudinal Stress in Concrete on Cross-Section at Mid-Height

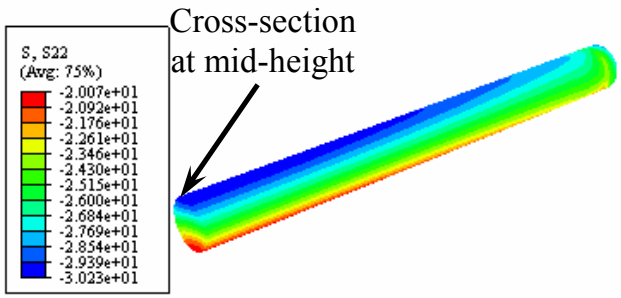

(a) Point 1

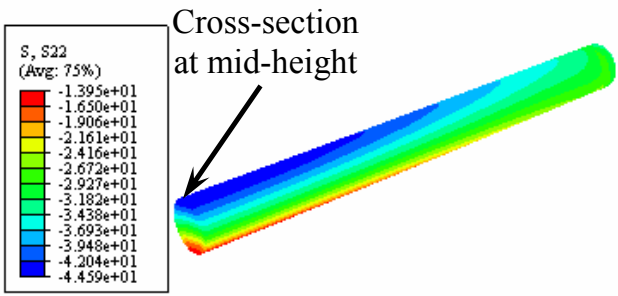

(b) Point 2

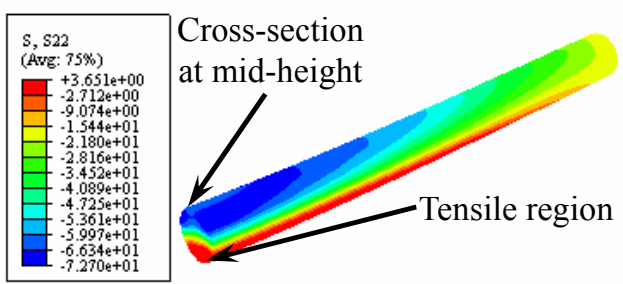

(c) Point 3

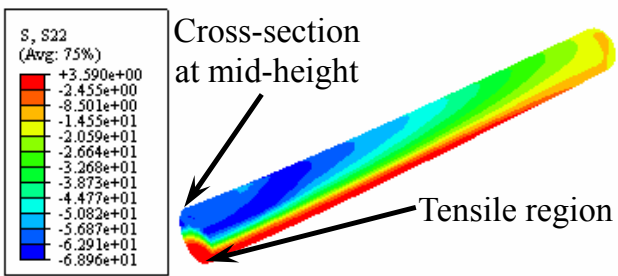

(d) Point 4 


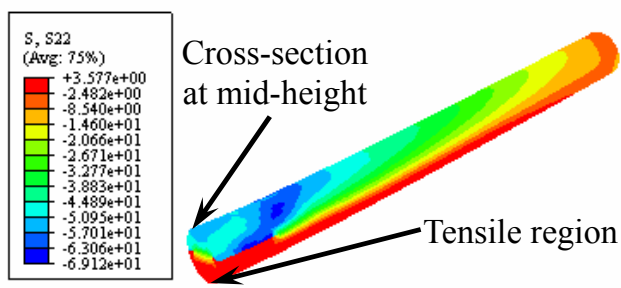

(e) Point 5

Figure 20. Distribution of Longitudinal Stress in Concrete in Axial Direction

\subsubsection{Longitudinal stress in steel tube}

Figure 21 shows the distribution of the longitudinal stress in the steel tube in axial direction. The cross-section of the concrete is under compression before the critical buckling load (point 2), while the longitudinal stress on the cross-section varies from compression to tension over the depth on the cross-section after point 3, which process performs from a positive to a negative value of the stresses. The maximum compressive and the maximum tensile stresses are located at the top and at the bottom surfaces respectively.

Figure 22 shows the distribution of the Mises stress in the steel tube. The loading at point 1 is relatively smaller and the steel tube is in elastic stage. At point 2, the compressed steel tube begins to yield and the cross-section at the mid-height yields firstly. At this time, the tensioned steel tube does not yet yield. Before the fracture of the transverse CFRP, the compressed steel tube is still in a yielding state. After the fracture of the transverse CFRP, the steel tube enters into a hardening stage.

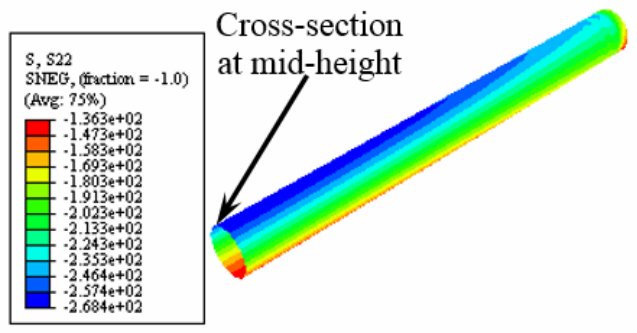

(a) Point 1

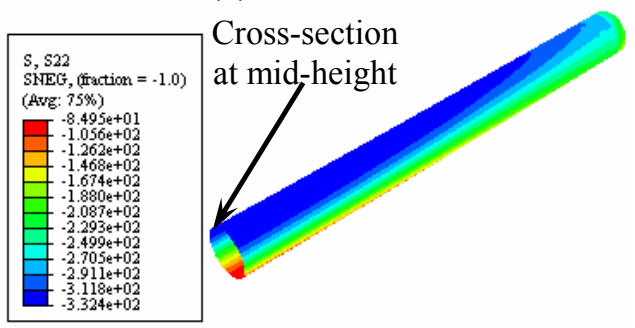

(b) Point 2 

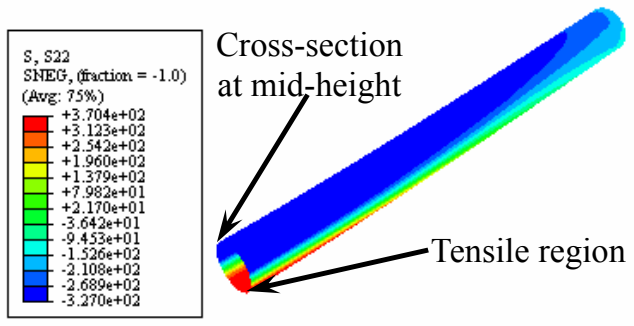

(c) Point 3
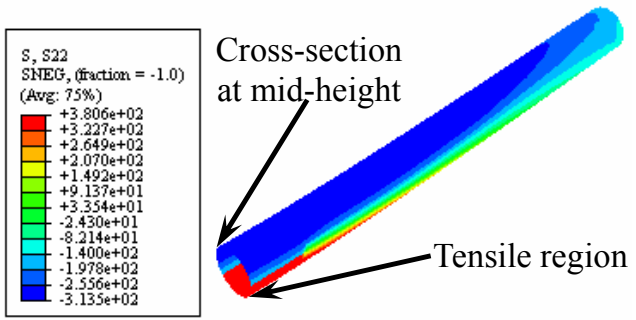

(d) Point 4
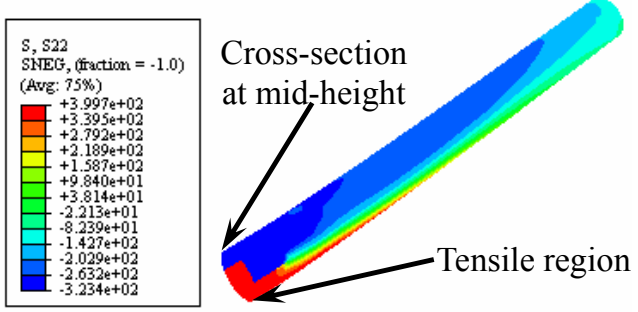

(e) Point 5

Figure 21. Distribution of Longitudinal Stress in Steel Tube in Axial Direction

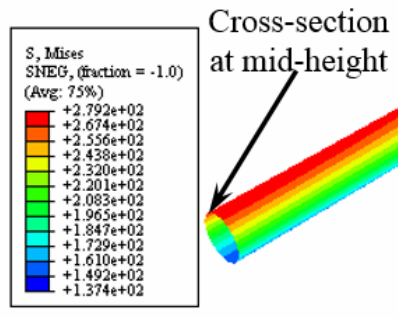

(a) Point 1

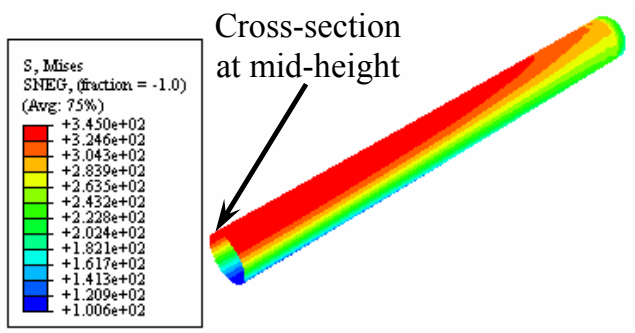

(b) Point 2 

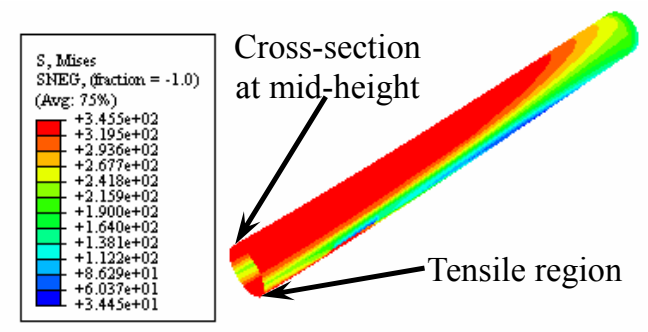

(c) Point 3
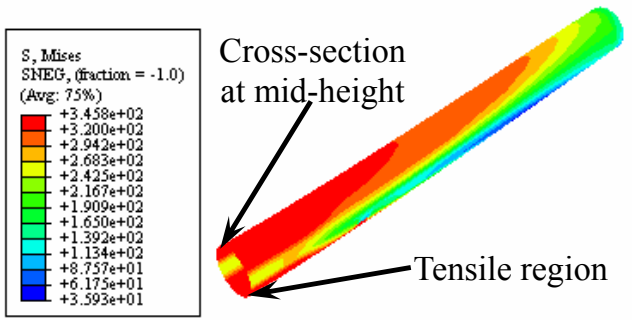

(d) Point 4
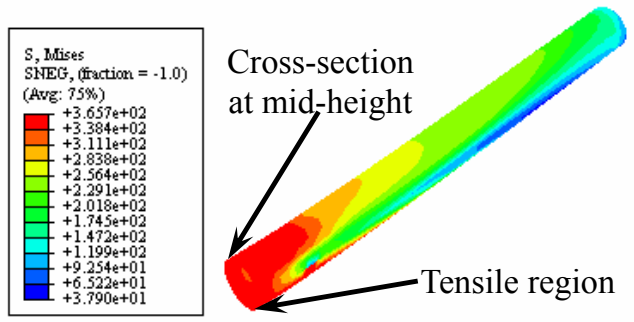

(e) Point 5

Figure 22. Distribution of Mises Stress in Steel Tube

\subsubsection{Stress in CFRPs}

Figure 23 shows the distribution of the stress in the transverse CFRP. Such stress has a uniform distribution in the longitudinal direction in the elastic stage (point 1). Before the critical buckling load, the stress in the compressive region on the cross-section at the mid-height increases gradually. However, the transverse CFRP is still not fractured (the maximum value of stress is about $0.17 f_{\text {cft }}$ ). With the increasing deflection at the mid-height, such stress increases continuously till the CFRP is fractured and does not work (point 3) which indicates that the transverse CFRP in the compressive region in longitudinal direction provides confinement but the transverse CFRP in the tensile region cannot produce such action in the entire loading process.

Figure 24 shows the distribution of the stress in the longitudinal CFRP. It is found that the stress in the longitudinal CFRP has a uniform distribution in the elastic stage (point 1). Before the critical buckling load (point 2), the stress in the tensile region on the cross-section at the mid-height is very small (about $0.001 \mathrm{MPa}$ ) because the deflection is about only $L / 250$, which indicates that the longitudinal CFRP does not provide strengthening effect to the column at this time. At point 3 , the deflection is about $L / 50$ and the stress in the longitudinal CFRP increases remarkably (the maximum value of the stress is about $0.57 f_{\text {cfl }}$ ). With the increasing deflection at the mid-height, the 
stress in the tensile region increases continuously till the CFRP is fractured and does not work. This shows the longitudinal CFRP in the tensile region detains the flexural deformation of the columns. The longitudinal CFRP in the compressive region cannot produce such action in the entire loading process.
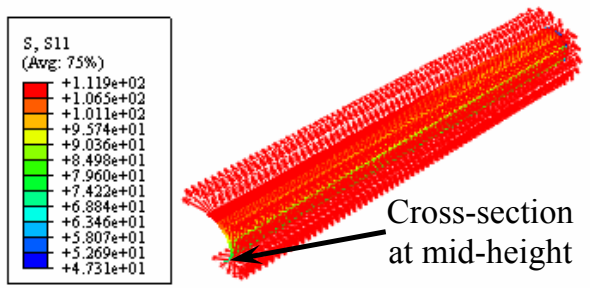

(a) Point 1
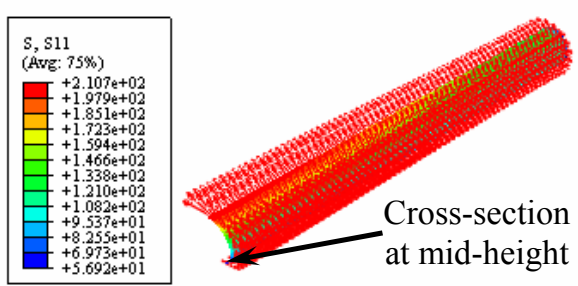

(b) Point 2
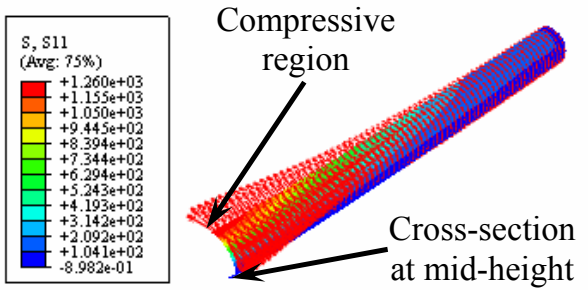

(c) Point 3
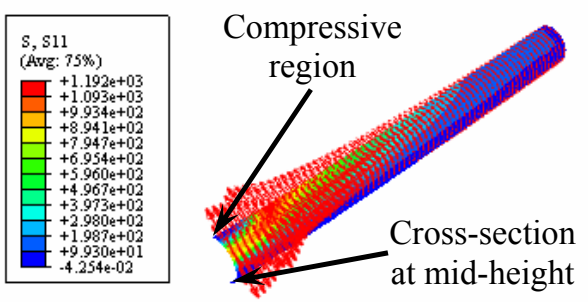

(d) Point 4 

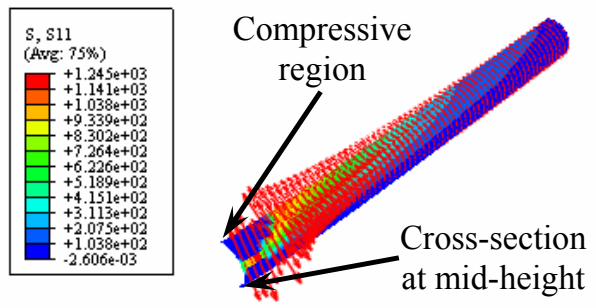

(e) Point 5

Figure 23. Distribution of Stress in Transverse CFRP

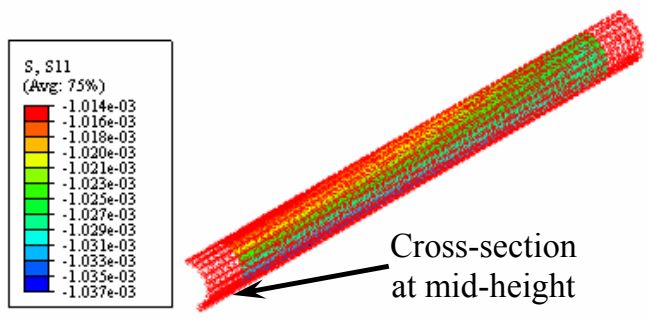

(a) Point 1
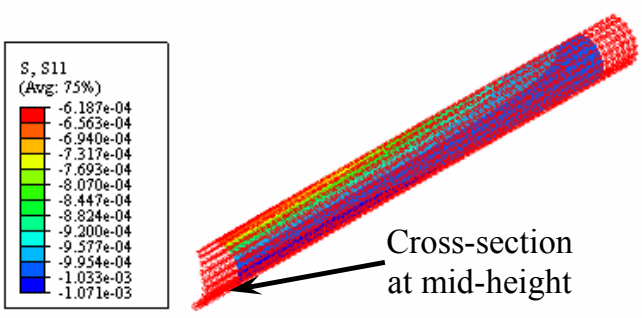

(b) Point 2

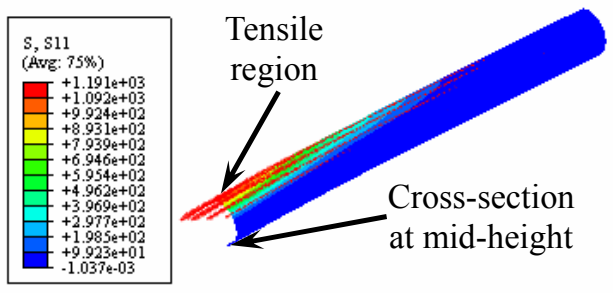

(c) Point 3

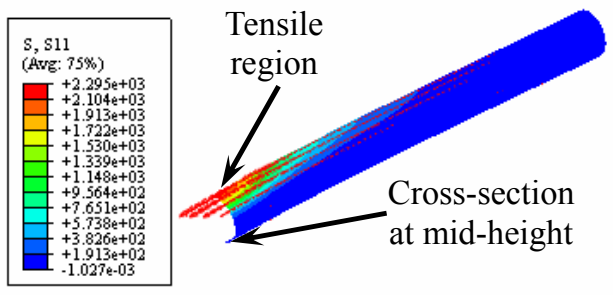

(d) Point 4 

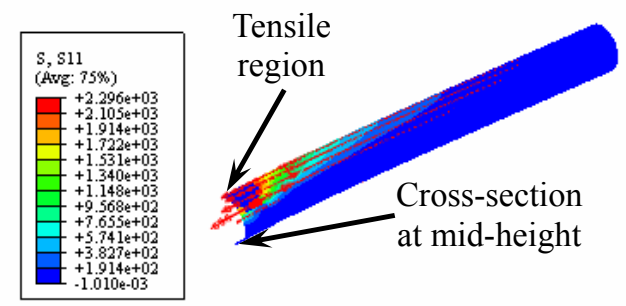

(e) Point 5

Figure 24. Distribution of Stress in Longitudinal CFRP

\subsection{Interaction Force between Concrete and Steel Tube}

The interaction force between the steel tube and the concrete $(p)$-deflection $\left(u_{\mathrm{m}}\right)$ curves for points $A, B$ and $C$ on the cross-section at the mid-height of the column is shown in Figure 25 . The interaction force in the compressive region is bigger than the corresponding one in the tensile region before the transverse CFRP in the compressive region (point $A$ ) is fractured (point 3 ). After the longitudinal CFRP in the tensile region (point $C$ ) is fractured (point 4), the interaction force at point $B$ becomes bigger than the one at point $A$ because the transverse CFRP at point $B$ is not fractured and it has still some confinements to the internal C-CFST.

The $p-u_{\mathrm{m}}$ curves of the columns at a height of $L / 2,3 L / 8$ and $L / 4$ to the end plate respectively in the compressive region are shown in Figure 26. The results show that the interaction force at the mid-height in the compressive region is bigger. With the increasing distance to the mid-height, the interaction force reduces gradually. As seen from Figures 25 and 26, for axially compressed C-CF-CFRP-ST columns with moderate slenderness ratio, the interaction force reduces continuously from the compressive region to the tensile region. In the compressive region, the interaction force also decreases gradually with the increasing distance to the mid-height of the specimens.

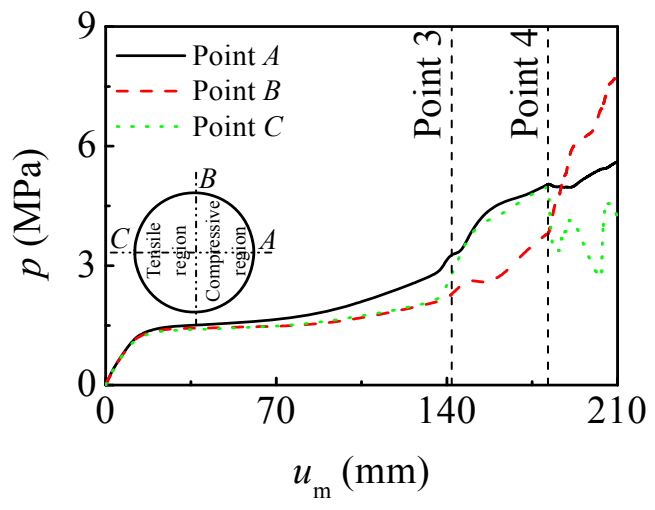

Figure 25. $p-u_{\mathrm{m}}$ Curves over Depth of Cross-Section of Column 


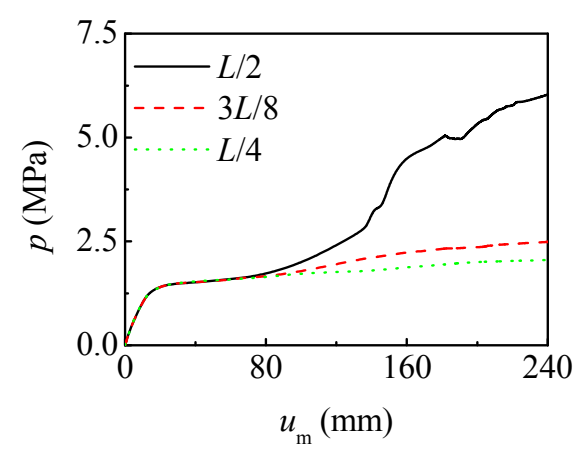

Figure 26. $p-u_{\mathrm{m}}$ Curves along Height of Column

\subsection{Analysis on Adhesive Strength}

To investigate the effect of the adhesive strength between the steel tube and the concrete on the performance of the axially compressed C-CF-CFRP-ST columns with moderate slenderness ratio, different friction factors $(\mu)$ with the values of $0,0.3$ and 0.6 respectively are selected in the simulation. Figure 27 shows the effect of the adhesive strength on the $N-u_{\mathrm{m}}$ curves of the column, which shows that the adhesive strength almost has no effect on the critical buckling load and the stiffness of the specimen in the elastic stage.

Figure 28 shows the effect of the adhesive strength on the $p-u_{\mathrm{m}}$ curves of the column. In the compressive region, $p$ increases with the increasing value of the friction factor $(\mu)$. A value from 0.3 to 0.6 seems to have no clear effect on $p$ in the tensile region, which is some different with the case that the value of $\mu$ is zero.

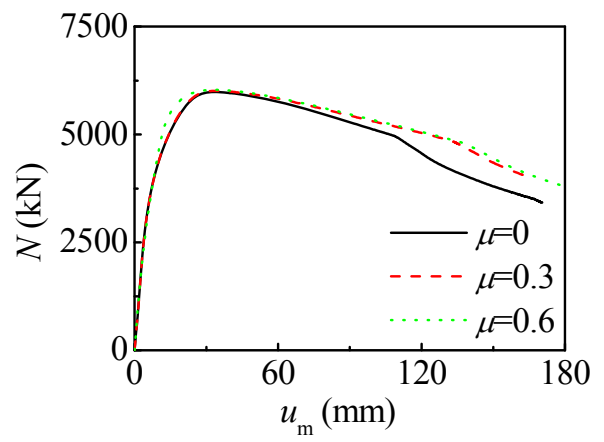

Figure 27. Influence of Adhesive Strength on $N-u_{\mathrm{m}}$ Curves of Column 


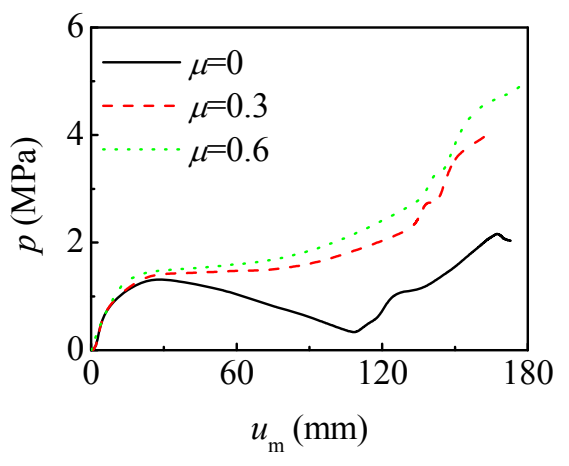

(a) Compressive region

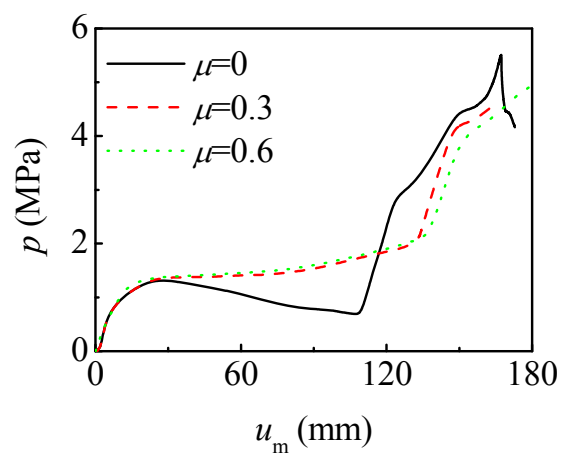

(b) Tensile region

Figure 28. Influence of Adhesive Strength on $p-u_{\mathrm{m}}$ Curves of Column

\section{CRITICAL BUCKLING LOAD}

\subsection{Calculation Expression}

Many calculated results $\left(f_{\mathrm{y}}=200-400 \mathrm{MPa}, f_{\mathrm{cu}}=30-120 \mathrm{MPa}, \xi_{\mathrm{s}}=0.2-4, \xi_{\mathrm{cf}}=0-0.6\right.$, $\left.\eta=0-0.9, E_{\mathrm{s}}=206 \mathrm{GPa}, v_{\mathrm{s}}=0.3, v_{\mathrm{c}}=0.2, E_{\mathrm{c}}=4700 \sqrt{f_{\mathrm{c}}} \mathrm{MPa}\right)$ show that the relationship between $\varphi$ (stability coefficient of the axially compressed C-CF-CFRP-CT columns with moderate slenderness ratio) and $\lambda$ can be described by using the curve that shown in Figure 29 (a). The curve can be divided into three stages: when $\lambda \leq \lambda_{0}, \varphi=1$, the column fails in strength; when $\lambda_{0}<\lambda \leq \lambda_{\mathrm{p}}$, the column fails in elasto-plastic buckling; when $\lambda>\lambda_{\mathrm{p}}$, the column fails in elastic buckling. $\lambda_{0}$ and $\lambda_{\mathrm{p}}$ are the limited slenderness ratios for an axially compressed C-CF-CFRP-ST column with moderate slenderness ratio in elasto-plastic buckling and elastic buckling respectively, and their values can be determined from the following equations (where the units of $f_{\mathrm{y}}$ and $f_{\mathrm{ck}}$ are in $\mathrm{MPa}$ ):

$$
\begin{aligned}
& \lambda_{0}=\pi \sqrt{(420 \xi+550) / f_{\text {cfscy }}} \\
& \lambda_{\mathrm{p}}=1743 / \sqrt{f_{\mathrm{y}}}
\end{aligned}
$$

where $\xi$ is the global confinement factor (Che et al. [19]); $f_{\text {cfscy }}$ is the index of load carrying capacity of the axially compressed C-CF-CFRP-ST stub columns (Che et al. [19]), where

$$
\begin{aligned}
& \xi=\xi_{\mathrm{s}}+\xi_{\mathrm{cf}} \\
& f_{\text {cfscy }}=\left[1.14+1.02\left(\xi_{\mathrm{s}}+3 \xi_{\mathrm{cf}}\right)\right] f_{\mathrm{ck}}
\end{aligned}
$$

By using regression analysis method (Han et al. [11]), relationship of $\varphi-\lambda$ can be expressed as follow 
$\varphi=\left\{\begin{array}{cc}1 & \left(\lambda \leq \lambda_{0}\right) \\ a \lambda^{2}+b \lambda+c & \left(\lambda_{0}<\lambda \leq \lambda_{\mathrm{p}}\right) \\ d /(\lambda+35)^{2} & \left(\lambda>\lambda_{\mathrm{p}}\right)\end{array}\right.$

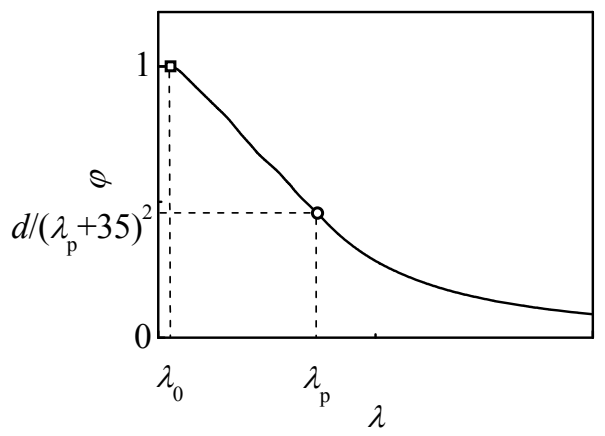

(a) $\varphi-\lambda$ curve

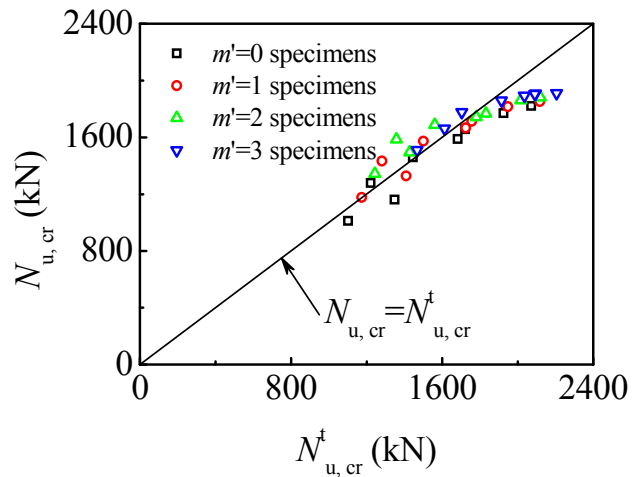

(b) Comparisons between $N_{\mathrm{u}, \mathrm{cr}}$ and $N_{\mathrm{u}, \mathrm{tr}}^{\mathrm{t}}$

Figure 29. Critical Buckling Load

where $a=\left[1+\left(35+2 \lambda_{\mathrm{p}}-\lambda_{0}\right) e\right] /\left(\lambda_{\mathrm{p}}-\lambda_{0}\right)^{2}, \quad b=e-2 a \lambda_{\mathrm{p}}, \quad c=1-a \lambda_{0}^{2}-b \lambda_{0}, \quad e=-d /\left(\lambda_{\mathrm{p}}+35\right)^{3}$, the expression of the coefficient $d$ is obtained from amounts of calculated results based on regression analysis, and it is listed as follow

$d=\left[13000+4657 \ln \left(\frac{235}{f_{\mathrm{y}}}\right)\right]\left(\frac{25}{f_{\mathrm{ck}}+5}\right)^{0.3}\left(\frac{\alpha}{0.1}\right)^{0.05}(1+\eta)^{0.9}$

where $\alpha=A_{\mathrm{s}} / A_{\mathrm{c}}$ is the steel ratio.

The expression for the critical buckling load of the C-CF-CFRP-ST columns with moderate slenderness ratio $\left(N_{\mathrm{u}, \mathrm{cr}}\right)$ is then expressed as follow

$N_{\mathrm{u}, \mathrm{cr}}=\varphi N_{\mathrm{u}}$

where $N_{\mathrm{u}}$ is the load carrying capacity of the C-CF-CFRP-ST stub columns (Che et al. [19]),

$$
N_{\mathrm{u}}=A_{\mathrm{cfsc}} f_{\mathrm{cfscy}}
$$

where $A_{\text {cfsc }}$ is the cross-sectional area of the C-CF-CFRP-ST columns with moderate slenderness ratio.

\section{$5.2 \quad$ Validation of Expression}

Figure 29 (b) displays the comparison between $N_{\mathrm{u}, \mathrm{cr}}$ and $N_{\mathrm{u}, \mathrm{cr}}^{\mathrm{t}}$ for the tested specimens. The average value of $N_{\mathrm{u}, \mathrm{cr}} / N_{\mathrm{u}, \mathrm{t} \text { cr }}^{\mathrm{t}}$ is 0.97 , and the mean square error is 0.08 which means the two results agree well and the calculated results are conservative in overall. 


\section{CONCLUSIONS}

Based on the presented results in this study, the following conclusions can be drawn: (1) for the axially compressed C-CF-CFRP-ST columns with moderate slenderness ratio, the specimens tend to fail in strength when the slenderness ratio is small while the ones with large slenderness ratio tend to fail in buckling. Load-deflection curves at the mid-height of the specimens can be divided into three stages: elastic, elasto-plastic and dropping stages. (2) The steel tube and the CFRP tube could cooperate well both in the transverse and in the longitudinal directions. The distribution of the longitudinal strain of the specimens over the depth on the cross-section approximately meets the plane section assumption. The longitudinal and the transverse strains at same point have opposite signs, and the tensioned steel tube in longitudinal direction has no confinement to the concrete. (3) The finite element simulation results of the deformed mode, the $N-u_{\mathrm{m}}$ curves and the $N-\Delta$ curves of the members as well as the stresses in the steel tube agree well with experimental results. The stress distributions of different composed materials have been analyzed, and the computed results have a good agreement with experimental results. (4) In the compressive region, with the increasing distance to the mid-height of the specimens, the interaction forces between the outer tube and the concrete reduces gradually. The adhesive strength has almost no effect on the critical buckling load and on the stiffness in the elastic stage of the specimens, but it can improve the confinement to the concrete. (5) The calculating equation of the critical buckling load of the axially compressed C-CF-CFRP-ST columns with moderate slenderness ratio is given.

\section{ACKNOWLEDGEMENTS}

The research reported in the paper is part of the Project 51378320 supported by Natural Science Foundation of China (NSFC) and the Project 2013003004 supported by Public Welfare Foundation of Liaoning Province, P. R. China. Their financial supports are highly appreciated.

\section{NOMENCLATURE}

$\begin{array}{ll}A_{\mathrm{c}} & : \text { Cross-sectional area of concrete } \\ A_{\mathrm{cfl}} & : \text { Cross-sectional area of longitudinal CFRP } \\ A_{\mathrm{cfsc}} & : \text { Cross-sectional area of C-CF-CFRP-ST columns with moderate slenderness ratio } \\ A_{\mathrm{cft}} & : \text { Cross-sectional area of transverse CFRP } \\ A_{\mathrm{s}} & : \text { Cross-sectional area of steel tube } \\ \text { C-CF-CFRP-ST } & : \text { Circular concrete filled CFRP-steel tubes } \\ \text { C-CFST } & : \text { Circular concrete filled steel tubes } \\ \text { CF-CFRP-ST } & : \text { Concrete filled CFRP-steel tubes } \\ \text { CF-FRP-T } & : \text { Concrete filled FRP tubes } \\ \text { CFRP } & : \text { Carbon fiber reinforced plastic } \\ \text { CFST } & : \text { Concrete filled steel tubes } \\ D_{\mathrm{s}} & : \text { Outer diameter of steel tube } \\ E_{\mathrm{c}} & : \text { Elasticity modulus of concrete } \\ E_{\mathrm{cf}} & : \text { Elasticity modulus of carbon fiber sheets } \\ E_{\mathrm{s}} & : \text { Elasticity modulus of steel tube } \\ f_{\mathrm{cfl}} & : \text { Ultimate tensile strength of longitudinal CFRP }\end{array}$


$f_{\text {cfscy }} \quad$ : Index of load carrying capacity of axially compressed C-CF-CFRP-ST stub

$f_{\mathrm{cft}}$ columns

$f_{\text {cf }}{ }^{\prime}$

: Ultimate tensile strength of transverse CFRP

$f_{\mathrm{ck}}$

: Tensile strength of carbon fiber sheet

$f_{\mathrm{c}}{ }^{\prime}$

: Characteristic axial compressive strength of concrete

$f_{\text {cu }}$

FRP

: Compressive strength of cylinder concrete specimens

$f_{\mathrm{y}}$

GFRP

$L$

LVDT

$m$

$m^{\prime}$

$N$

$N_{\mathrm{u}}$

$N_{\text {u,cr }}$

: Cubic strength of concrete specimen

: Fiber reinforced plastic

: Yield strength of steel tube

: Glass fiber reinforced plastic

: Length of specimens

: Linear variable differential transformer

: Number of transverse CFRP layer

: Number of longitudinal CFRP layer (s)

: Axial load

: Load carrying capacity of C-CF-CFRP-ST stub columns

$N_{\mathrm{u}, \mathrm{cr}}^{\mathrm{t}}$

: Calculated value of critical buckling load of C-CF-CFRP-ST columns with moderate slenderness ratio

: Tested value of critical buckling load of C-CF-CFRP-ST columns with moderate slenderness ratio

$p \quad:$ Interaction force between concrete and outer tube

S-CF-CFRP-ST : Square concrete filled CFRP-steel tubes

$t_{\mathrm{cf}} \quad:$ Thickness of 1 layer carbon fiber sheet

$t_{\mathrm{s}} \quad:$ Wall thickness of steel tube

$u_{\mathrm{m}} \quad:$ Deflection at mid-height of column

$v_{\mathrm{c}} \quad:$ Elasticity Poisson's ratio of concrete

$v_{\mathrm{s}} \quad:$ Elasticity Poisson' ratio of steel tube

$w_{\mathrm{cf}} \quad:$ Density of carbon fiber sheet

$\alpha \quad:$ Steel ratio

$\delta_{\text {cf }} \quad:$ Elongation percentage of carbon fiber sheet

$\Delta$

$\varepsilon_{\text {cf }}$

$\varepsilon_{\mathrm{cfl}}$

$\varepsilon_{\mathrm{cflr}}$

$\varepsilon_{\mathrm{cft}}$

: Axial shortening of specimen

: Strain of CFRP

: Strain of Longitudinal CFRP

: Rupture strain of longitudinal CFRP

$\varepsilon_{\mathrm{cftr}}$

: Strain of transverse CFRP

$\varepsilon_{1}$

$\varepsilon_{\mathrm{s}}$

: Rupture strain of transverse CFRP

: Longitudinal strain

: Strain of steel tube

$\varepsilon_{\mathrm{sl}}$

: Longitudinal strain of steel tube

$\varepsilon_{\mathrm{st}}$

: Transverse strain of steel tube

$\varepsilon_{\mathrm{t}}$

: Transverse strain

$\varphi$

: Stability coefficient of axially compressed C-CF-CFRP-ST columns with moderate slenderness ratio 


$\begin{array}{ll}\eta & : \text { Strengthening factor of longitudinal CFRP } \\ \lambda & : \text { Slenderness ratio } \\ \lambda_{\mathrm{o}} & : \text { Limited slenderness ratio for an axially compressed C-CF-CFRP-ST column with } \\ \lambda_{\mathrm{p}} & \begin{array}{l}\text { moderate slenderness ratio in elasto-plastic buckling } \\ \text { : Limited slenderness ratio for an axially compressed C-CF-CFRP-ST column with } \\ \mu\end{array} \\ \text { moderate slenderness ratio in elastic buckling } \\ \sigma_{\mathrm{cf}} & : \text { Friction factor } \\ \xi & : \text { Stress of CFRP } \\ \xi_{\mathrm{cf}} & : \text { Global confinement factor } \\ \xi_{\mathrm{s}} & : \text { Confinement factor of transverse CFRP }\end{array}$

\section{REFERENCES}

[1] Wang, Y.C. and Restrepo, J.I., "Investigation of Concentrically Loaded Reinforced Columns Confined with Glass Fiber-reinforced Polymer Jackets", ACI Structure Journal, 2001, Vol. 98 , No. 3, pp. 377-385.

[2] Fam, A.Z. and Rizkalla, S.H., "Confinement Model for Axially Loaded Concrete Confined by Circular FRP Tubes”, ACI Structure Journal, 2001, Vol. 98, No. 4, pp. 451-461.

[3] Teng, J.G., Chen, J.F., Smith, S.T. and Lam, L., "FRP Strengthened RC Structures", John Wiley \& Sons, 2002, Chichester, UK.

[4] Karabinis, A.I., Rousakis, T.C. and Manolitsi, G.E., "3D Finite Element Analysis of Substandard Columns Strengthened by Fiber Reinforced Polymer Sheets”, ASCE Journal of Composites for Construction, 2008, Vol. 12, No. 5, pp. 531-540.

[5] Rousakis, T.C., Karabinis, A.I., Kiousis, P.D. and Tepfers, R., "Analytical Modelling of Plastic Behaviour of Uniformly FRP Confined Concrete Members", Journal of Composites Part B: Engineering, 2008, Vol. 39, No. 7-8, pp. 1104-1113.

[6] Yu, T., Teng, J.G., Wong, Y.L. and Dong, S.L., "Finite Element Modeling of Confined Concrete-I: Drucker-Prager Type Plasticity Model”, Engineering Structures, 2010, Vol. 32, No. 3, pp. 665-679.

[7] Yu, T., Teng, J. G., Wong, Y. L. and Dong, S. L., "Finite Element Modeling of Confined Concrete-II: Plastic-Damage Model”, Engineering Structures, 2010, Vol. 32, No. 3, pp. 680-691.

[8] Jiang, J. F. and Wu, Y. F., "Identification of Material Parameters for Drucker-Prager Plasticity Model for FRP Confined Circular Concrete Columns", International Journal of Solids and Structures, 2012, Vol. 49, No. 3-4, pp. 445-456.

[9] Han, L. H., "Tests on Concrete Filled Steel Tubular Columns with High Slenderness Ratio", Advances in Structural Engineering, 2000, Vol. 3, No. 4, pp. 337-344.

[10] Han, L. H., Zhao, X. L. and Tao, Z., "Tests and Mechanics Model of Concrete-Filled SHS Stub Columns, Columns and Beam-Columns", Steel and Composite Structures, 2001, Vol. 1 No. 1, pp. 51-74.

[11] Han, L. H., Yao, G. H. and Zhao, X. L., "Behavior and Calculation on Concrete-Filled Steel CHS (Circular Hollow Section) Beam-Columns", Steel and Composite Structures, 2004, Vol. 4, No. 3, pp. 169-188.

[12] Han, L.H., Yao, G.H. and Zhao, X.L., "Tests and Calculations for Hollow Structural Steel (HSS) Stub Columns Filled with Self-Consolidating Concrete (SCC)", Journal of Constructional Steel Research, 2005, Vol. 61, No. 9, pp. 1241-1269.

[13] Han, L. H. and Li, W., "Seismic Performance of CFST Column to Steel Beam Joint with RC Slab: Experiments", Journal of Constructional Steel Research, 2010, Vol. 66, No. 11, PP. 
1374-1386.

[14] Han, L. H., "Fire Resistance of Concrete Filled Steel Tubular Columns", Advances in Structural Engineering, 1998, Vol. 2, No. 1, pp. 35-39.

[15] Han, L.H., Yao, G.H. and Tao, Z., "Performance of Concrete-filled Thin-walled Steel Tubes under Pure Torsion", Thin Walled Structures, 2007, Vol. 45, No. 1, pp. 24-36.

[16] Han, L.H., Liu, W. and Yang, Y. F., "Behaviour of Concrete-filled Steel Tubular Stub Columns Subjected to Axially Local Compression", Journal of Constructional Steel Research, 2008, Vol. 64, No. 4, pp. 377-387.

[17] Han, L. H., Hou, C. and Wang, Q. L., "Square Concrete Filled Steel Tubular (CFST) Members under Loading and Chloride Corrosion: Experiments", Journal of Constructional Steel Research, 2012, Vol. 71, No. 1, pp. 11-25.

[18] Han, L. H., Hou, C. C. and Wang, Q. L., "Behavior of Circular CFST Stub Columns under Sustained Load and Chloride Corrosion", Journal of Constructional Steel Research, 2014, Vol. 103, No. 1, pp. 23-36.

[19] Che, Y., Wang, Q. L. and Shao, Y. B., "Compressive Performances of the Concrete Filled Circular CFRP-Steel Tube (C-CFRP-CFST)". International Journal of Advanced Steel Construction, 2012, Vol. 8 No. 4, pp. 311-338.

[20] Tao, Z., Han, L. H. and Wang, L. L., "Compressive and Flexural Behaviour of CFRP Repaired Concrete-filled Steel Tubes after Exposure to Fire”, Journal of Constructional Steel Research, 2007, Vol. 63, No. 8, pp. 1116-1126.

[21] Tao, Z., Wang, Z. B., Han, L. H. and Uy B., "Fire Performance of Concrete-Filled Steel Tubular Columns Strengthened by CFRP”, Steel and Composite Structures, 2011, Vol. 11, No. 4, pp. 307-324.

[22] Xiao, Y., He, W. H. and Choi, K. K., "Confined Concrete-filled Tubular Columns.” Journal of Structural Engineering, 2005, Vol. 131, No. 3, pp. 488-497.

[23] Choi, K. K. and Xiao, Y., "Analytical Model of Circular CFRP Confined Concrete-filled Steel Tubular Columns under Axial Compression", Journal of Composites for Construction, 2010, Vol. 14, No. 1, pp. 125-133.

[24] Park, J. W., Hong, Y. K., Hong, G. S., Kim, J. H. and Choi, S. M., "Design Formulas of Concrete Filled Circular Steel Tubes Reinforced by Carbon Fiber Reinforced Plastic Sheets", Procedia Engineering, 2011, Vol. 14, pp. 2916-2922.

[25] Hu, Y. M., Yu, T. and Teng, J. G., "FRP-Confined Circular Concrete-Filled Thin Steel Tubes under Axial Compression", Journal of Composites for Construction, 2011, Vol. 15, No. 5, pp. 850-860.

[26] Li, S. Q., Chen, J. F., Bisby, L. A., Hu, Y. M. and Teng, J. G., "Strain Efficiency of FRP Jackets in FRP-Confined Concrete-Filled Circular Steel Tubes", International Journal of Structural Stability and Dynamics, 2012, Vol. 12, No. 1, pp. 75-94.

[27] Teng, J. G., Hu, Y. M. and Yu, T., "Stress-Strain Model for Concrete in FRP-Confined Steel Tubular Columns", Engineering Structures, 2013, Vol. 49, No. 4, pp. 156-167.

[28] Wang, Q. L. and Shao, Y. B., "Flexural Performance of Circular Concrete Filled CFRP-Steel Tubes". Advanced Steel Construction, 2015, Vol. 11, No. 2, pp. 127-149.

[29] Tao, Z., Han, L. H. and Zhuang, J. P., "Axial Loading Behavior of CFRP Strengthened Concrete-Filled Steel Tubular Stub Columns", Advances in Structural Engineering, 2007, Vol. 10, No. 1, pp. 37-46.

[30] Park, J. W., Hong, Y. K. and Choi, S. M., "Behaviors of Concrete Filled Square Steel Tubes Confined by Carbon Fiber Sheets (CFS) under Compression and Cyclic Loads", Steel and Composite Structures, 2010, Vol. 10, No. 2, pp. 187-205.

[31] Sundarraja, M. C. and Ganesh, P. G., "Investigation on Strengthening of CFST Members under Compression Using CFRP Composites", Journal of Reinforced Plastics and Composites, 2011, Vol. 30, No. 15, pp. 1251-1264. 
[32] Sundarraja, M. C. and Ganesh, P. G., "Experimental Study on CFST Members Strengthened by CFRP Composite under Compression", Journal of Constructional Steel Research, 2012, Vol. 72, No. 5, pp. 75-83.

[33] Sundarraja, M. C. and Ganesh, P. G., "Behaviour of CFST Members under Compression Externally Reinforced by CFRP Composites", Journal of Civil Engineering and Management, 2013, Vol. 19, No. 2, pp. 184-195.

[34] Wang, Q. L. and Shao, Y. B., "Compressive Performances of Concrete Filled Square CFRP-Steel Tubes (S-CFRP-CFST)”, Steel and Composite Structures, 2014, Vol. 14, No. 5, pp. 455-480.

[35] Sundarraja, M. C. and Ganesh, P. G., "Finite Element Modeling of CFRP Jacketed CFST Members under Flexural Loading". Thin-walled Structures, 2011, Vol. 49, No. 12, pp. 1483-1491.

[36] Wang, Q. L., Li, J., Shao, Y. B. and Zhao, W. J., "Flexural Performances of Square Concrete Filled CFRP-Steel Tubes (S-CF-CFRP-ST)", Advances in Structural Engineering, 2015, Vol. 18, No. 8, pp. 1319-1344.

[37] Yu, T., Wong, Y. L., Teng, J. G., Dong, S. L. and Lam, E. S. S., "Flexural Behavior of Hybrid FRP-Concrete-Steel Double-skin Tubular Members", Journal of Composites for Construction, 2006, Vol. 10, No. 5, pp. 443-452. 